\title{
Western North Pacific Tropical Cyclone Tracks in CMIP5 Models: Statistical Assessment Using a Model-Independent Detection and Tracking Scheme
}

\author{
SAMUEl S. BELl AND SAVIN S. CHAND \\ Centre for Informatics and Applied Optimization, Federation University Australia, Ballarat, Australia \\ SuZANA J. CAMARGO \\ Lamont-Doherty Earth Observatory of Columbia University, Palisades, New York \\ KEVIN J. TORY \\ Research and Development Branch, Bureau of Meteorology, Melbourne, Australia \\ CHRIS TURVILLE \\ Centre for Informatics and Applied Optimization, Federation University Australia, Ballarat, Australia \\ HARVEY YE \\ Research and Development Branch, Bureau of Meteorology, Melbourne, Australia
}

(Manuscript received 21 November 2018, in final form 11 June 2019)

\begin{abstract}
Past studies have shown that tropical cyclone (TC) projection results can be sensitive to different types of TC tracking schemes, and that the relative adjustments of detection criteria to accommodate different models may not necessarily provide a consistent platform for comparison of projection results. Here, future climate projections of TC activity in the western North Pacific basin (WNP, defined from $0^{\circ}-50^{\circ} \mathrm{N}$ and $100^{\circ} \mathrm{E}-180^{\circ}$ ) are assessed with a model-independent detection and tracking scheme. This scheme is applied to models from phase 5 of the Coupled Model Intercomparison Project (CMIP5) forced under the historical and representative concentration pathway 8.5 (RCP8.5) conditions. TC tracks from the observed records and independent models are analyzed simultaneously with a curve-clustering algorithm, allowing observed and model tracks to be projected onto the same set of clusters $(k=9)$. Four of the nine clusters were projected to undergo significant changes in TC frequency. Straight-moving TCs in the South China Sea were projected to significantly decrease. Projected increases in TC frequency were found poleward of $20^{\circ} \mathrm{N}$ and east of $160^{\circ} \mathrm{E}$, consistent with changes in ascending motion, as well as vertical wind shear and relative humidity respectively. Projections of TC track exposure indicated significant reductions for southern China and the Philippines and significant increases for the Korean peninsula and Japan, although very few model TCs reached the latter subtropical regions in comparison to the observations. The use of a fundamentally different detection methodology that overcomes the detector/tracker bias gives increased certainty to projections as best as lowresolution simulations can offer.
\end{abstract}

\section{Introduction}

Numerous climate projection studies have been undertaken on the highly active western North Pacific (WNP) tropical cyclone (TC) basin leading toward a growing consensus on TC frequency, genesis location, and track projection results. Such studies generally

Corresponding author: Samuel S. Bell, ss.bell@federation.edu.au utilize one of three methods to investigate TC behaviors in climate models: 1) direct simulation, 2) downscaling, or 3) use of large-scale genesis indices. An advantage of direct simulation over the other two methods is that other than limitations inherent in the models and detection algorithm, no additional assumptions are required [see Emanuel (2013) for further reading]. Both fine $(\sim 20-50 \mathrm{~km})$ and coarse $(\sim 100-300 \mathrm{~km})$ resolution climate models have been used for direct simulation of 
TCs in the WNP (e.g., Bengtsson et al. 2007; Stowasser et al. 2007; Sugi et al. 2009; Zhao et al. 2009; Held and Zhao 2011; Murakami et al. 2011; Scoccimarro et al. 2011; Murakami et al. 2012a,b; Camargo 2013; Mori et al. 2013; Strachan et al. 2013; Vecchi et al. 2013; Vecchi et al. 2014; Walsh et al. 2013; Yokoi et al. 2013; Knutson et al. 2015; Murakami et al. 2015; Camargo et al. 2016; Jin et al. 2016; Kossin et al. 2016; Tsou et al. 2016; Nakamura et al. 2017). Although TC intensities are poorly resolved in coarse-resolution models (e.g., Davis 2018), they can have relatively good representations of the large-scale processes that affect TC characteristics such as genesis locations and tracks (e.g., Moise et al. 2015; Chand et al. 2017), which are the focus of the present study; other projections such as TC rainfall and intensity were not made. We stress that such models are an important tool for providing useful information on future projections of TC genesis and tracks, especially considering the abundance of coarseresolution climate models that are readily available for climate projection studies.

Experiments from phase 3 (CMIP3; Meehl et al. 2007) and phase 5 (CMIP5; Taylor et al. 2012) of the Coupled Model Intercomparison Project are two such sources of coarse-resolution models for projection studies. Kossin et al. (2016) and Nakamura et al. (2017) included in their analyses CMIP5 TC-like storms obtained by direct simulation to analyze WNP TC frequencies, genesis locations, and tracks, along with downscaled synthetic TCs; in the case of Nakamura et al. (2017), TCs from high-resolution simulations were also analyzed. For the CMIP5 model TC-like storms, both these studies utilized the same detection and tracking algorithm of Camargo and Zebiak (2002). Since all detectors have strengths and weaknesses, different detectors can produce very different results when applied to the same model (Horn et al. 2014; Tory et al. 2014) and so we argue that coarse-resolution simulations for the WNP basin are worth revisiting with a fundamentally different detection methodology.

The Camargo and Zebiak (2002) algorithm uses objectively determined thresholds developed within the model under consideration, in which there can be some compensation between model error and detector error that could partly mask model errors (Tory et al. 2013a,b). This is particularly problematic for low-resolution models and weak storms (Horn et al. 2014), typical of TCs directly simulated in CMIP5 models. Therefore, to test the veracity of the conclusions in the previous studies, and to provide a thorough assessment of climate model performance, and thus provide greater confidence in projection results, a similar assessment of TC tracks is undertaken here using the threshold-independent TC detection and tracking algorithm developed by Tory et al. (2013a), called Okubo-Weiss-Zeta (OWZ). This algorithm is fundamentally different in design from those used in many other studies (e.g., Shaevitz et al. 2014; Horn et al. 2014) and has been used previously for CMIP5 TC projection studies (e.g., Tory et al. 2013c; Chand et al. 2017; Bell et al. 2019a,b)

The tuning of this detection algorithm in ERAInterim reanalysis data, though not exclusive to this algorithm (e.g., TempestExtremes; Zarzycki and Ullrich 2017), and the use of only large-scale environmental parameters allow a level of circumvention of detectorrelated dependencies on model resolution (Walsh et al. 2007; Tory et al. 2013b; Wehner et al. 2015). Thus the detector can be applied to, and objectively assess, different CMIP5 models without requiring resolution- or basin-specific adjustments. This enables the present study to offer complementary results of CMIP5 model assessments and projections of WNP TCs to those presented in Camargo (2013), Nakamura et al. (2017), and other studies. More broadly, projection results given by the present study can also form a basis of comparison with those of other studies involving fine-resolution direct simulations, downscaling, or genesis indices.

In the present study, a multimodel mean of TC detections is constructed to best match several observed TC climatology features over the historical period 19702000. TCs simulated under historical conditions are then compared to TCs projected under high radiative forcing conditions [representative concentration pathway 8.5 (RCP8.5)]. The detection and tracking scheme of Tory et al. (2013a) is used to simulate TCs in each model. In contrast to prior studies, we construct our multimodel mean and cross-validate our results while taking due consideration of the interdependencies that exist between certain CMIP5 models (e.g., Knutti et al. 2013; Sanderson et al. 2015). An objective TC track cluster analysis (Gaffney 2004; Gaffney et al. 2007) is also performed in line with prior studies in the WNP (e.g., Camargo et al. 2007a,b; Nakamura et al. 2017) to provide quantitative regional-scale assessments of both model and observed TC tracks. For consistency, we use an objective definition of a "TC track" following Bell et al. (2018) where a track begins at the TC declaration location ${ }^{1}$ and terminates if found to be located poleward of a subtropical jet (Tory and Dare 2015).

Achieving a consensus on future TC characteristics in the WNP basin becomes more important when

\footnotetext{
${ }^{1}$ The TC declaration location of OWZ detected tracks was shown to be consistent with a TC first reaching a 10-min sustained wind speed of $17 \mathrm{~m} \mathrm{~s}^{-1}$ in IBTrACS.
} 
considering the impacts of TC landfalls. Future landfall rates are likely to depend on the relationship between greenhouse warming and TC genesis location, frequency, and track direction. Projection studies such as this will therefore be of great societal value in coming decades, in terms of best developing risk-mitigation strategies and concentrating future preparation efforts to the most high-risk areas. The WNP basin is home to the most frequent TCs on the planet and is situated right beside the densely populated coastal regions of eastern Asia (e.g., Japan, the Korean peninsula, and China) and southeastern Asia (e.g., the Philippines and Thailand; see Fig. 1 for geographical locations of these countries). Generally, these countries experience several TC landfalls each year, owing to the mean westward and northwestward steering flows during the active TC season (e.g., Harr and Elsberry 1995; Zhang et al. 2018). El Niño-Southern Oscillation has also been shown to modulate TC landfall rates (Wu et al. 2004), while a recent study suggested that sea surface temperature teleconnections from the North Atlantic can also affect TC landfall rates over East Asia (Gao et al. 2018). In this study, we also evaluate the exposure of these countries to TC incidences as a result of greenhouse warming.

The outline of this paper is as follows. Section 2 contains data, definitions, and methods used in this study. Section 3 evaluates the performance of the OWZ scheme in the WNP using selected CMIP5 models, and provides projection results between the late twentiethand twenty-first-century simulations. Finally, section 4 provides a summary and discussion of our results with respect to previous studies undertaken in the WNP basin.

\section{Data, definitions, and methods}

\section{a. Observational data}

The Joint Typhoon Warning Center (JTWC) best track dataset (JTWC 2017) is used in this study to give a baseline of TC climatological characteristics over the historical period 1970-2000. TC tracks were sampled every $6 \mathrm{~h}$ (at 0000, 0600, 1200 and 1800 UTC). To be consistent with tracks detected in climate models, observed TC tracks begin at the location a storm reaches a 10-min sustained wind speed of $17 \mathrm{~m} \mathrm{~s}^{-1}$ [i.e., when a TC reaches $35 \mathrm{kt}\left(1 \mathrm{kt} \approx 0.51 \mathrm{~m} \mathrm{~s}^{-1}\right)$ in JTWC (1-min sustained)] with those storms not reaching this intensity excluded from the analyses. Much like the tracks detected in the CMIP5 models (as discussed in section 2d), observed tracks are terminated in two cases: 1) if a forecast center no longer tracks them (i.e., track information ceases in the database) or 2) after 1979, if they encounter an objectively diagnosed subtropical jet as they move poleward (Tory and Dare 2015); the subtropical jet criterion also isolates TCs from those that may form as nontropical systems in the subtropics.

\section{b. CMIP5 model data}

Twelve models from CMIP5 (Taylor et al. 2012) are used in this study (Table 1), as they were deemed to simulate reasonable TC climatologies of TC frequency and select ENSO features with the OWZ detection scheme (Tory et al. 2013c; Chand et al. 2017). The current generation of climate models produced by the CMIP experiments provides a wide array of platforms to assess current and future climate scenarios. The two scenarios assessed in this work are 1) historical simulations (1970-2000) to evaluate and assess the ability of climate models to simulate observed TC climatology and 2) RCP8.5 projections (2070-2100) to determine projected changes as a result of global warming. Future climate CMIP5 simulations are often implemented with one of several representative concentration pathways (e.g., van Vuuren et al. 2011) to control the level of carbon emissions in the atmosphere compared to preindustrial times. In this study, the RCP8.5 scenario that represents a maximum $8.5 \mathrm{~W} \mathrm{~m}^{-2}$ likely increase in radiative forcing over preindustrial levels (Riahi et al. 2011) was chosen to best elucidate any changing TC behavior in a warmer climate (e.g., Chand et al. 2017).

\section{c. Detection and tracking}

The Okubo-Weiss-Zeta TC detection and tracking algorithm (Tory et al. 2013a) is used in this study to detect and track TCs in all models without any adjustment of thresholds to accommodate different model resolutions. The OWZ algorithm has undergone scrupulous validation in reanalysis data in terms of annual TC numbers and genesis positions (Tory et al. 2013b), and more recently in terms of tracks (Bell et al. 2018). Key details of the OWZ algorithm are provided in Tory et al. (2013a) while a good summary of the algorithm can be found in the appendix of this paper. Crucially, the track validation study of Bell et al. (2018) identified a limitation in the algorithm, suggesting that those TCs lasting less than 2 days after declaration should be discarded for best performance. This study implements this suggestion by removing all such detected TCs.

\section{d. TC track definition}

The objective definition of a TC track established in Bell et al. (2018) is also used in the present study. This definition states that a TC track detected by the OWZ algorithm commences from the TC declaration location (as this location best matched the timing of a TC first reaching the 10-min sustained wind speed of $17 \mathrm{~m} \mathrm{~s}^{-1}$ in 


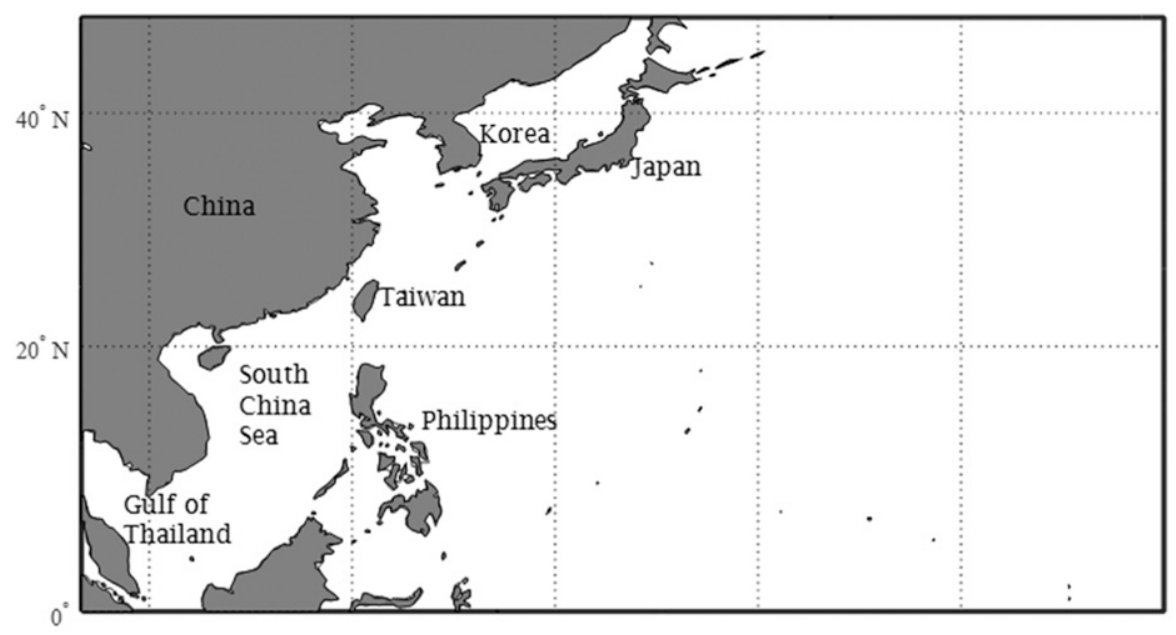

$120^{\circ} \mathrm{E}$

$150^{\circ} \mathrm{E}$

$180^{\circ} \mathrm{E}$
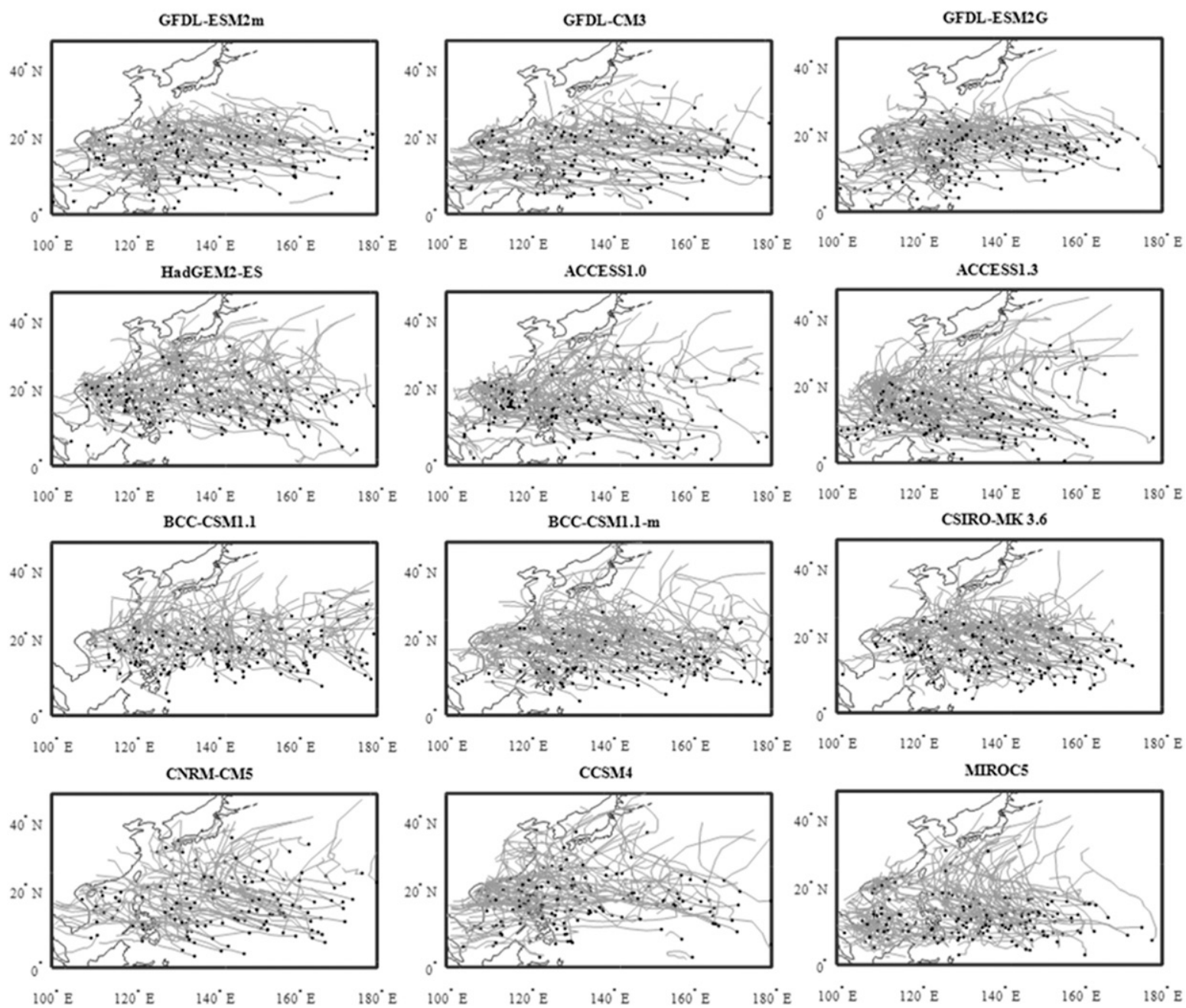

FIG. 1. Map of the WNP basin and TC tracks detected by the Tory et al. (2013a) scheme in 12 CMIP5 models' historical simulations (1970-2000). A random sample of 200 tracks is shown for each individual model. 
TABLE 1. Annual frequency of TCs over the historical climate period (1970-2000) in the WNP basin (genesis between $100^{\circ} \mathrm{E}$ and $\left.180^{\circ}\right)$ and several genesis subregions. Annual TC counts during the peak 3-month seasonal period [August-October (ASO)] are also included. Models with an asterisk (*) combine to form a mean of six models (6-M). The models CNRM-CM5 and CCSM4, denoted by a plus sign $(+)$, are combined to form "1 model" in the 6-M. (Expansions of acronyms are available online at http://www.ametsoc.org/ PubsAcronymList.)

\begin{tabular}{|c|c|c|c|c|c|c|c|c|c|c|}
\hline & $\begin{array}{c}\text { West } \\
\left(<140^{\circ} \mathrm{E}\right)\end{array}$ & $\begin{array}{c}\text { East } \\
\left(>140^{\circ} \mathrm{E}\right)\end{array}$ & $\begin{array}{l}\text { North } \\
\left(>20^{\circ} \mathrm{N}\right)\end{array}$ & $\begin{array}{l}\text { Ratio } \\
\text { W/E }\end{array}$ & $\begin{array}{l}\text { Ratio } \\
\text { N/Total }\end{array}$ & ASO & $\begin{array}{l}\text { Ratio } \\
\text { ASO/ } \\
\text { Total }\end{array}$ & $\begin{array}{l}\text { Total } \\
\left(\mathrm{yr}^{-1}\right)\end{array}$ & $\begin{array}{l}\text { Horizontal } \\
\text { resolution }\end{array}$ & Reference \\
\hline Observed & 15 & 10.3 & 5.2 & 1.45 & 0.21 & 13.6 & 0.54 & 25.3 & - & JTWC (2017) \\
\hline GFDL CM3 & 7.9 & 6.7 & 2.6 & 1.18 & 0.18 & 5.9 & 0.40 & 14.6 & $2.5^{\circ}$ & Donner et al. (2011) \\
\hline GFDL-ESM2G* & 14.6 & 8.4 & 3.8 & 1.74 & 0.16 & 10.9 & 0.47 & 23.1 & $2.5^{\circ}$ & Donner et al. (2011) \\
\hline GFDL-ESM2M & 10.8 & 10.4 & 3.5 & 1.04 & 0.17 & 10.8 & 0.51 & 21.2 & $2.5^{\circ}$ & Donner et al. (2011) \\
\hline ACCESS1.0 & 9.7 & 5.4 & 2.5 & 1.8 & 0.17 & 9.8 & 0.65 & 15.1 & $1.9^{\circ}$ & Bi et al. (2012) \\
\hline ACCESS1.3* & 14 & 7.9 & 3.4 & 1.77 & 0.16 & 11.8 & 0.54 & 21.9 & $1.9^{\circ}$ & Bi et al. (2012) \\
\hline HadGEM2 & 11.1 & 9.1 & 4.8 & 1.22 & 0.24 & 12.7 & 0.63 & 20.2 & $1.9^{\circ}$ & Jones et al. (2011) \\
\hline BCC_CSM1.1 & 8.2 & 8 & 3.6 & 1.03 & 0.22 & 9 & 0.56 & 16.2 & $2.8^{\circ}$ & Wu et al. (2014) \\
\hline BCC_CSM1.1m* & 8.7 & 10.3 & 3 & 0.84 & 0.16 & 9.7 & 0.51 & 18.9 & $1.1^{\circ}$ & Wu et al. (2014) \\
\hline CSIRO Mk3.6.0* & 15.4 & 16.4 & 5.7 & 0.94 & 0.18 & 15.5 & 0.49 & 31.8 & $1.9^{\circ}$ & Collier et al. (2011) \\
\hline $\mathrm{CNRM}^{-\mathrm{CM} 5^{+}}$ & 4.3 & 4.3 & 2.1 & 1 & 0.25 & 3.7 & 0.44 & 8.5 & $1.4^{\circ}$ & Voldoire et al. (2013) \\
\hline $\mathrm{CCSM}_{4}^{+}$ & 8.8 & 4.6 & 3.1 & 1.91 & 0.23 & 6.9 & 0.51 & 13.4 & $1.2^{\circ}$ & Gent et al. (2011) \\
\hline $\mathrm{CNRM}+\mathrm{CCSM}^{*}$ & 13.1 & 8.9 & 5.2 & 1.47 & 0.24 & 10.6 & 0.48 & 22.0 & - & \\
\hline MIROC5* & 12.8 & 8 & 1.3 & 1.6 & 0.06 & 8.5 & 0.41 & 20.8 & $1.4^{\circ}$ & $\begin{array}{l}\text { Watanabe et al. } \\
\text { (2010) }\end{array}$ \\
\hline $6-\mathrm{M}$ & 15.4 & 11.6 & 4.4 & 1.3 & 0.16 & 13.1 & 0.48 & 27 & - & \\
\hline
\end{tabular}

best track data) and terminates when a TC either dissipates or encounters an objectively diagnosed subtropical jet, identified in the reanalysis and model data by a $200-\mathrm{hPa}$ jet steam $>25 \mathrm{~m} \mathrm{~s}^{-1}$ and zonal winds exceeding $15 \mathrm{~m} \mathrm{~s}^{-1}$ [see Tory and Dare (2015) for details].

\section{e. Cluster analysis}

The probabilistic curve-clustering (CC) technique of Gaffney (Gaffney 2004; Gaffney et al. 2007) is applied to group together TC tracks of similar properties in the WNP basin. The cluster analysis was first implemented separately on the observed and historically simulated track data, and later run with all track data combined (denoted "all-in-one"). At least 25 cluster runs were performed on each set of data. In each run, the input order of the tracks was randomized and 12 iterations of the expected maximization (EM) algorithm were used. For each set of data, the cluster run with the smallest trained log-likelihood value was selected. Following prior studies (e.g., Camargo et al. 2007a, $\mathrm{b}^{2}$ ) linear regression mixture (lrm) models of second-order polynomials were fitted to tracks with an objectively determined number of clusters $k$. Camargo et al.

\footnotetext{
${ }^{2}$ It is important to note that Camargo et al. $(2007 \mathrm{a}, \mathrm{b})$ used a different period and basin definition than considered here, namely the JTWC best track dataset over the period 1950-2002, and included storms that formed outside the WNP basin that later entered the region.
}

(2007a,b) used seven $(k=7)$ clusters to describe the observed WNP TC tracks and the same choice was used when comparing with model tracks in Nakamura et al. (2017) and Patricola et al. (2018). To be consistent with those studies, the present study also initially used seven clusters to describe WNP TC tracks. However, we additionally introduced two more clusters to account for discrepancies between observed and model data.

\section{f. Detection comparison with Camargo (2013)}

Altogether 12 CMIP5 models are used in this study (Table 1). Six of these models were also assessed with the TC detection and tracking scheme of Camargo and Zebiak (2002), hereafter the C-Z scheme, in Camargo (2013) under historical and RCP8.5 conditions. These tracks were acquired and adjusted to match the OWZ tracks in this study (e.g., terminated upon reaching a subtropical jet, and aligned to the first track position of OWZ systems; see appendix B herein). This enabled a direct comparison between this detection scheme $(\mathrm{C}-\mathrm{Z})$ and the OWZ in terms of simulating projected changes in TC frequencies between the historical and RCP8.5 climate simulations (Table 2). The annual average number of TCs detected by the C-Z scheme tends to be less in historical conditions compared to those obtained via the OWZ scheme. For example, CCSM4 produces 13.4 TCs per year using the OWZ scheme but only 0.7 TCs per year using the C-Z scheme. Similarly, GFDLESM2M produces 21.2 TCs per year using the OWZ scheme but 9.3 TCs with the C-Z scheme, with the 
TABLE 2. A comparison of annual CMIP5 model detections in the WNP between the Tory et al. (2013a) scheme (OWZ) and the Camargo and Zebiak (2002) scheme (C-Z) under historical conditions (1970-2000) and the RCP8.5 condition (2070-2100). Agreement between the detectors on the projected sign of change in TC frequency are in bold. A dash (-) indicates that TC frequencies between the two climate simulations were not significantly different.

\begin{tabular}{|c|c|c|c|c|c|c|}
\hline \multirow{2}{*}{$\begin{array}{c}\text { Model } \\
\text { Detector }\end{array}$} & \multicolumn{2}{|c|}{ Historical $\left(\operatorname{Ref}_{\mathrm{OBS}}=25.3\right)$} & \multicolumn{2}{|c|}{ RCP8.5 } & \multicolumn{2}{|c|}{ Projection sign agreement } \\
\hline & OWZ & $\mathrm{C}-\mathrm{Z}$ & OWZ & $\mathrm{C}-\mathrm{Z}$ & OWZ & $\mathrm{C}-\mathrm{Z}$ \\
\hline GFDL-ESM2M & 21.2 & 9.3 & 21.5 & 13.3 & - & $\uparrow$ \\
\hline GFDL CM3 & 14.6 & 9.4 & 10.3 & 6.2 & $\downarrow$ & $\downarrow$ \\
\hline HadGEM2-ES & 20.2 & 4.7 & 20.2 & 3.1 & - & $\downarrow$ \\
\hline CSIRO-Mk3.6.0 & 31.8 & 16.9 & 33.3 & 15.5 & - & $\downarrow$ \\
\hline CCSM4 & 13.4 & 0.7 & 13.6 & 1.6 & - & $\uparrow$ \\
\hline MIROC5 & 20.8 & 4.6 & 13.6 & 1.8 & $\downarrow$ & $\downarrow$ \\
\hline
\end{tabular}

reference observed annual climatology being 25.3. However, models generally project TC numbers to increase or decrease in the same direction (except CSIRO Mk3.6) between the two detection schemes, while small differences in magnitude causes some model projections to be statistically insignificant (Table 2).

These results highlight how consistently defined detector thresholds are important for assessing and evaluating climate models, and consequently having a better understanding of uncertainties associated with projection results. In the next section, we discuss in detail how the OWZ-detected TCs in different climate models compare with the observations, as well as make assessments of future projections for the entire WNP basin and individual countries using a select group of models.

\section{Results}

\section{a. Preliminary assessment of model tracks}

Historical TC tracks detected by the OWZ algorithm in the 12 CMIP5 models over the years 1970-2000 are shown in Fig. 1. Notably, some models produced by the same institution (three GFDL models, two BCC and ACCESS models), display similar track climatology such as geographical TC genesis distribution and track shape. It is here that we acknowledge the work of Knutti et al. (2013) and Sanderson et al. (2015), who constructed a "family tree" of climate models highlighting the interdependencies that exist between some CMIP5 models and how these can impact on the results of multimodel experiments. We place each model into one of four subgroups based on their analyses: the first three subgroups comprise models that exhibit similar control states and responses to the RCP8.5 scenario (e.g., Knutti et al. 2013) and are either produced by the same institution or based on the same model. The remaining "independent" models are placed into a fourth subgroup to simplify analyses. The model subgroups are as follows:
- GFDL: GFDL-ESM2M, GFDL CM3, and GFDLESM2G.

- HAD-ACC: HadGEM2-ES, ACCESS1.0, and ACCESS1.3.

- BCC: BCC_CSM1.1 and BCC_CSM1.1m.

- CCC-M: CSIRO Mk3.6, CCSM4, CNRM-CM5, and MIROC5

Multimodel TC tracks from each "subgroup" were then compared to the observations by using measures of their genesis density, mean track trajectory, and track density (Fig. 2). Even though genesis densities between models were reasonably well simulated overall, three out of four subgroups (i.e., GFDL, BCC, and CCC-M) showed evidence of an eastward bias in genesis locations (Fig. 2, top panel). Notably, Zhang et al. (2017) also found an eastward genesis bias using a variation of GFDL CM3. In the Gulf of Thailand (see Fig. 1 for geographical locations), all subgroups except BCC seem to have overestimated the genesis density. See Tory et al. (2018) for further reading.

Mean track trajectories in each model subgroup (as indicated by a preliminary cluster analysis) showed varied degrees of simulation of the observed trajectories (Fig. 2, middle panel). For example, simulation of recurving tracks reaching high latitudes around Japan is lacking in all subgroups, as also noted in prior works (e.g., Zhao et al. 2009; Bell et al. 2018). The HAD-ACC models appear to be the most consistent in simulating these types of recurving tracks, while the GFDL models show little or no recurvature in their mean track trajectories. This contrasts with Camargo (2013) where GFDL models show a complete recurvature of tracks (her Fig. 1). This could be either due to the difference in TC tracks definitions between the two studies, as Camargo (2013) considered entire detected track length and we terminated it as soon as a TC encountered a subtropical jet, or the OWZ scheme is unable to capture the recurving tracks in the GFDL models. Furthermore, comparisons of track densities (Fig. 2; bottom panel) 

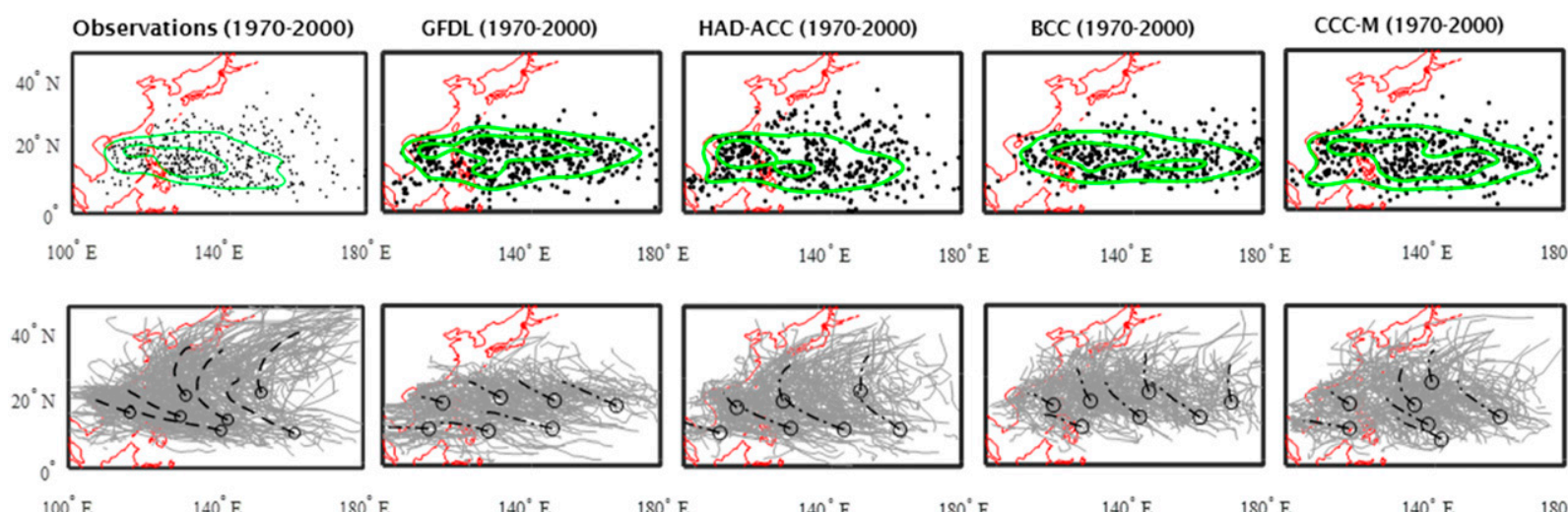

$140^{\circ} \mathrm{E}$

$180^{\circ} \mathrm{E}$

$140^{\circ} \mathrm{E}$

$180^{\circ} \mathrm{E}$

$140^{\circ} \mathrm{E}$

$180^{\circ} \mathrm{E}$
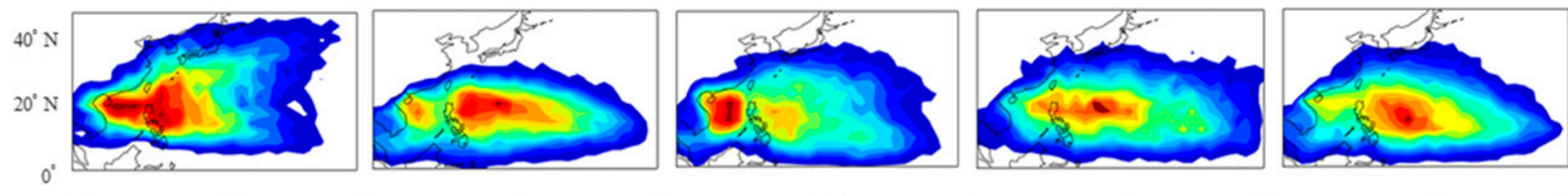

$100^{\circ} \mathrm{E}$

$140^{\circ} \mathrm{E}$

$180^{\circ} \mathrm{E}$

0.5

$140^{\circ} \mathrm{E}$

$180^{\circ} \mathrm{E}$

$140^{\circ} \mathrm{E}$

$180^{\circ} \mathrm{E}$

$140^{\circ} \mathrm{E}$

$180^{\circ} \mathrm{E}$

$140^{\circ} \mathrm{E}$

$180^{\circ} \mathrm{E}$

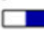

1

1.5

FIG. 2. (top) TC genesis (random sample of 400) kernel density estimates enclose $33 \%$ and $66 \%$ of TC genesis (green contours). (middle) TC tracks (random sample of 400) and (bottom) mean track density (average annual number of individual TCs entering or forming within a $2.5^{\circ} \times 2.5^{\circ}$ grid box, smoothed). In the middle row, a preliminary cluster analysis $(k=7)$ was run on each set of data. Mean track trajectories are shown in black.

further highlight some of these regional-scale deficiencies between model subgroups, such as limitations in tracking TCs at subtropical latitudes near Japan and the Korean peninsula.

\section{b. Selection of models for cluster analysis}

A good way to reduce the biases that exist within individual CMIP5 models is to combine them into a multimodel mean. The next question that follows is which of our 12 models to include in such a mean. To avoid autocorrelation-related errors, our first stipulation is that only one model from each of the first three subgroups defined in the prior section may become be part of the multimodel mean. This leaves us with seven potential models to choose from. Our next stipulation is that, combined, the models should realistically represent the observed TC climatology. Table 1 details several measures of TC climatology features for each model in the WNP basin, mainly those of TC frequency and geographical genesis location. Noticeably, some "independent" models underestimate the observed annual TC climatology $\left(\operatorname{Ref}_{\mathrm{Obs}}=25.3\right)$. This can become problematic when comparing observed TC frequencies with model frequencies if they are to comprise the multimodel mean. However, it was found that combining CCSM4 and CNRM-CM5 (CNRM+CCSM; Table 1) produced climatology measures (i.e., TC frequency and genesis distribution) similar to those of the observations. Treating the latter as one model, this was combined with five other models (GFDL-ESM2G, ACCESS1.3, BCC_CSM1.1m, CSIRO Mk3.6, and MIROC5) to form a six-model mean (6-M). TC climatology measures of the 6-M were also very similar with the observations (Table 1).

\section{c. "All-in-one" cluster analysis}

Next, a curve clustering analysis (Gaffney 2004; Gaffney et al. 2007) is run to objectively compare the historically observed and 6-M climate tracks. However, as is indicated by the middle panel of Fig. 2, cluster analyses run on separate data do not always produce the same solutions (i.e., location of clusters). So it was not surprising that a cluster analysis on the 6-M tracks using seven clusters $(k=7)$ did not produce a solution where all clusters were comparable to the observed clusters (not shown). Through trial and error, using values of $k$ from 7 to 13 (not shown), it was found that nine clusters ( $k=9$; not shown) enabled the best comparison with the original seven observed clusters (see Fig. 2, and also Camargo et al. 2007a,b; Nakamura et al. 2017).

To ensure the clusters are objectively comparable for projections, the cluster analysis $(k=9)$ is performed with observed tracks, historical 6-M tracks, and projected (RCP8.5) 6-M tracks all input to the clustering algorithm simultaneously (i.e., all-in-one). This allows projection of tracks onto the same set of clusters (Fig. 3). 

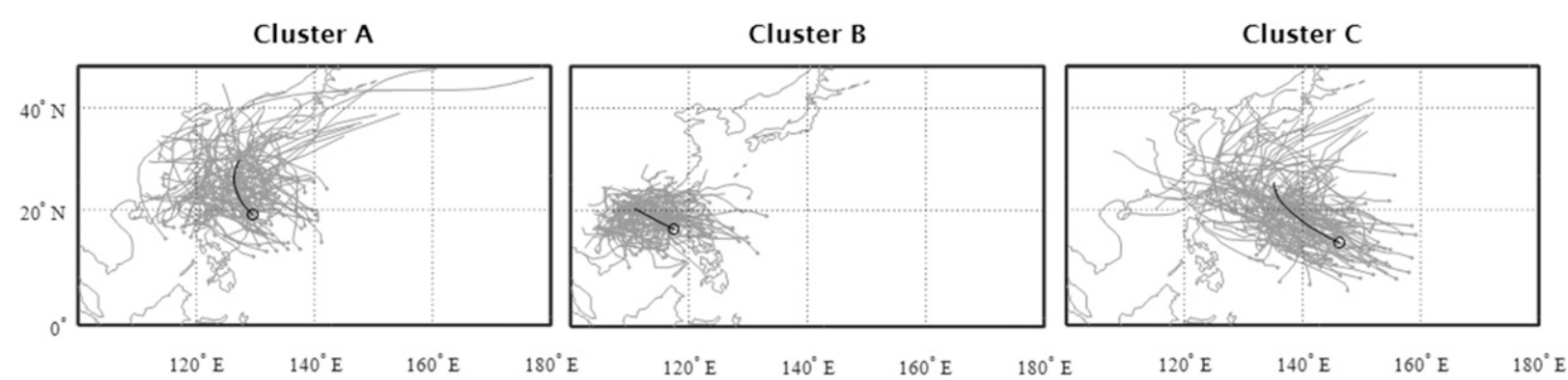

Cluster D

Cluster $\mathrm{E}$

Cluster $\mathrm{F}$
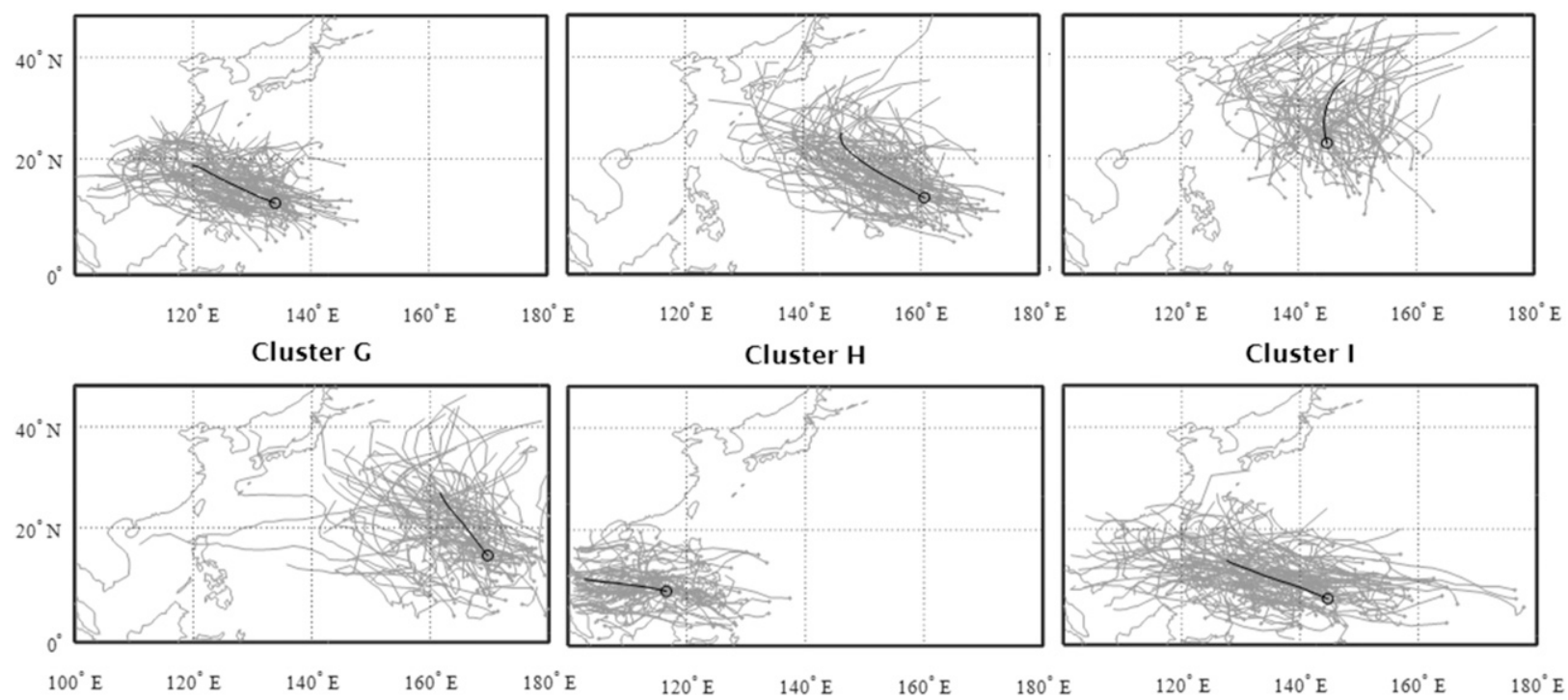

FIG. 3. Results of the "all-in-one" cluster analysis, which includes observed and model tracks together. Mean track trajectories for each cluster are displayed in black, with a sample of individual tracks in grayscale. See Tables 3 and 4 for the composition of each cluster.

Note that the locations of the all-in-one clusters were very similar to the cluster analysis run solely on the historical 6-M tracks. The composition breakdown of each cluster is divided into two tables: Table 2 compares observed and historically simulated TC frequencies, while Table 3 compares historically simulated TC frequencies with the projected $\mathrm{TC}$ frequencies under RCP8.5. It is found that the historical 6-M overestimates TCs in the Gulf of Thailand (cluster $\mathrm{H}$ ) by $74 \%$ (or $\sim 1.2$ TCs per year), perhaps due to incorrect identification of tropical depressions as TCs in some models. The historical 6-M also underestimates higher-latitude TC clusters (clusters $\mathrm{F}$ and $\mathrm{A}$ ), and also TCs near the equator in the far east of the basin (cluster G). Despite these inconsistencies, as well as shortcomings in tracking TCs recurving in westerlies at high latitude above Japan (section 3a), the 6-M is generally doing well in simulating a realistic historical TC climatology.

\section{d. Future projections}

In additional to regular "raw" projections between historical and projected climates, TC frequency detection biases may be factored into projection calculations as a further measure of confidence. We apply a simple climate-scale bias correction strategy (e.g., Ho et al. 2012; Hawkins et al. 2013) to correct the number of TCs in the future climate projection using results from the historical model simulations and observations (under

TABLE 3. Mean annual composition of TC frequencies in each cluster. Simulated error is calculated by [(historical - observed)/ observed].

\begin{tabular}{lccc}
\hline \hline Cluster & $\begin{array}{c}\text { Observed } \\
(1970-2000)\end{array}$ & $\begin{array}{c}\text { Historical } \\
(1970-2000)\end{array}$ & $\begin{array}{c}\text { Simulated } \\
\text { error }(\%)\end{array}$ \\
\hline A & 3.9 & 3.2 & -19 \\
B & 4.0 & 3.3 & -18 \\
C & 2.9 & 3.2 & +11 \\
D & 3.3 & 2.8 & -17 \\
E & 2.0 & 2.6 & +31 \\
F & 3.7 & 2.2 & -40 \\
G & 2.3 & 1.3 & -40 \\
H & 1.6 & 2.8 & +74 \\
I & 2.8 & 1.7 & -42 \\
\hline
\end{tabular}




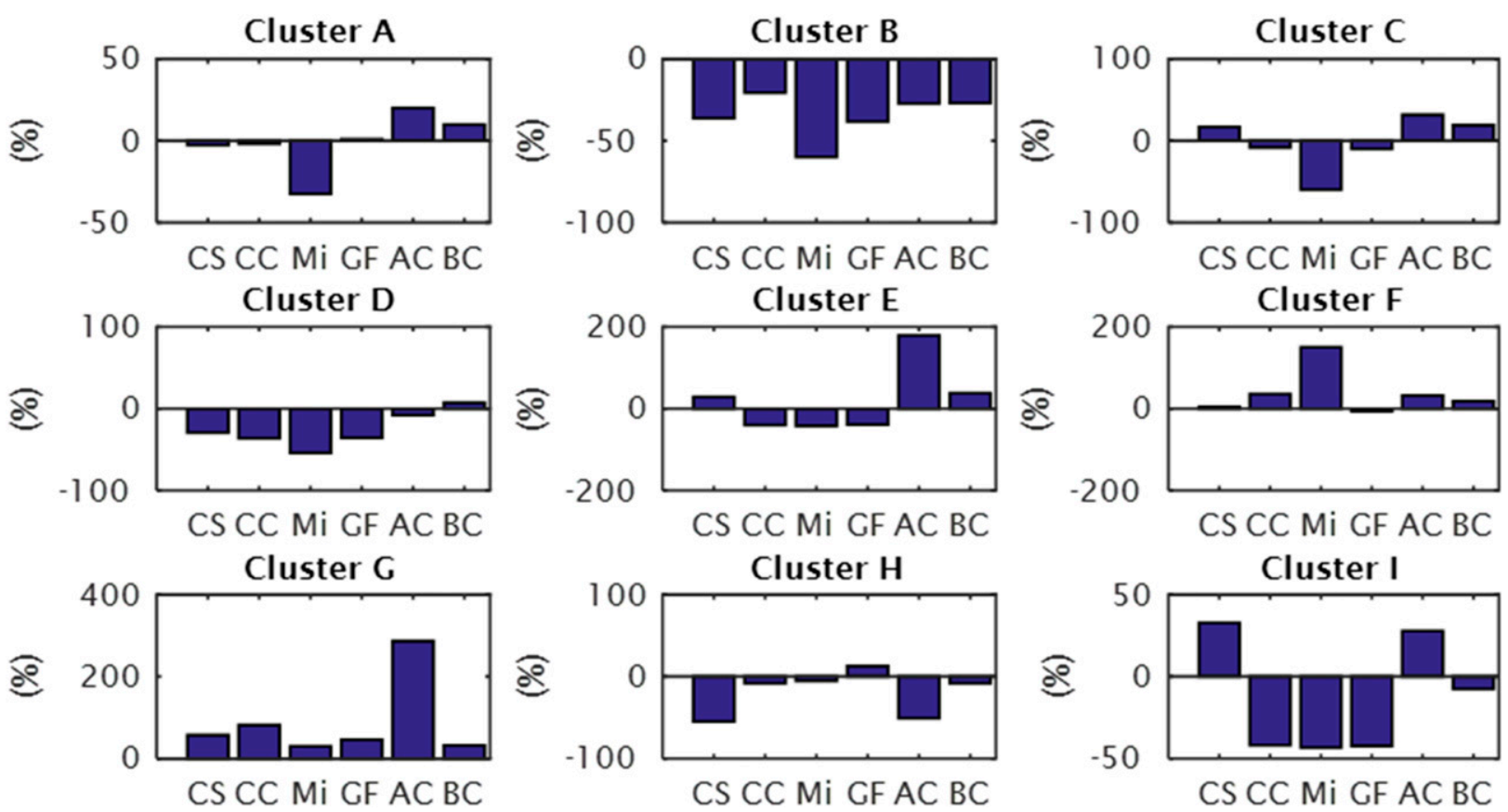

FIG. 4. Percentage change of TC frequencies in each cluster between the RCP8.5 and historical climate simulations for individual models that comprise the 6-M. CS = CSIRO Mk3.6, CC = CCSM4 + CNRM-CM5, Mi = MIROC5, GF = GFDL-ESM2G, AC = ACCESS1.3, BC = BCC_CSM1.1m.

the assumption that the variability in models and observations are the same) such that

$$
F_{\mathrm{Adj}}=F_{\mathrm{RAW}}+\left(O_{\mathrm{REF}}-C_{\mathrm{REF}}\right),
$$

where $F_{\text {Adj }}$ represents the adjusted future-climate TC numbers, $F_{\mathrm{RAW}}$ represents raw future-climate (RCP8.5) TC numbers, $O_{\mathrm{REF}}$ denotes observed TC numbers, and $C_{\mathrm{REF}}$ represents raw historical TC numbers. Furthermore,

$$
P_{\mathrm{Adv}}=\left(F_{\mathrm{Adv}}-O_{\mathrm{REF}}\right) / O_{\mathrm{REF}},
$$

where $P_{\text {Adj }}$ represents an adjusted percentage projected change in TC numbers.
Projections changes in TC frequency for individual models within the 6-M for each cluster (Fig. 4) give an indication of the significance of the changes in annual TC frequencies under RCP8.5 (Table 4). This significance test of sign is based on a binomial distribution under the assumption that each model has an equal chance of more or fewer TCs in the projected climate. These results (Table 4; Fig. 4) indicate significantly decreased TC frequency for the two straight-moving clusters in the South China Sea (clusters B and D), and increased TC frequency above $20^{\circ} \mathrm{N}$ (cluster F) and also east of $160^{\circ} \mathrm{E}$ nearer the equator (cluster $\mathrm{G}$ ). These results are generally in line with the studies of Murakami et al. (2011), Kossin et al. (2016), and Nakamura et al. (2017).

TABLE 4. Mean annual composition of TC frequencies in each cluster. Raw projected change is calculated by [(RCP8.5 - historical)/ historical]. See Eq. (1) for adjusted projection calculations. Confidence in the sign of the raw projections is based on results between

\begin{tabular}{|c|c|c|c|c|c|}
\hline Cluster & Historical (1970-2000) & RCP8.5 (2070-2100) & Raw projection (\%) & Adjusted projection (\%) & Confidence \\
\hline A & 3.2 & 3.2 & -1 & -1 & $34 \%$ \\
\hline $\mathrm{B}$ & 3.3 & 2.1 & -35 & -29 & $>95 \%$ \\
\hline $\mathrm{C}$ & 3.2 & 3.2 & -2 & -2 & $34 \%$ \\
\hline $\mathrm{D}$ & 2.8 & 2.0 & -27 & -22 & $90 \%$ \\
\hline $\mathrm{E}$ & 2.6 & 3.0 & +13 & +17 & $34 \%$ \\
\hline $\mathrm{F}$ & 2.2 & 2.7 & +25 & +15 & $90 \%$ \\
\hline $\mathrm{G}$ & 1.3 & 2.3 & +70 & +42 & $>95 \%$ \\
\hline $\mathrm{H}$ & 2.8 & 2.3 & -17 & -29 & $66 \%$ \\
\hline I & 1.7 & 1.5 & -6 & -4 & $66 \%$ \\
\hline
\end{tabular}
individual models in the 6-M (see Fig. 4); values above $90 \%$ are in bold. 


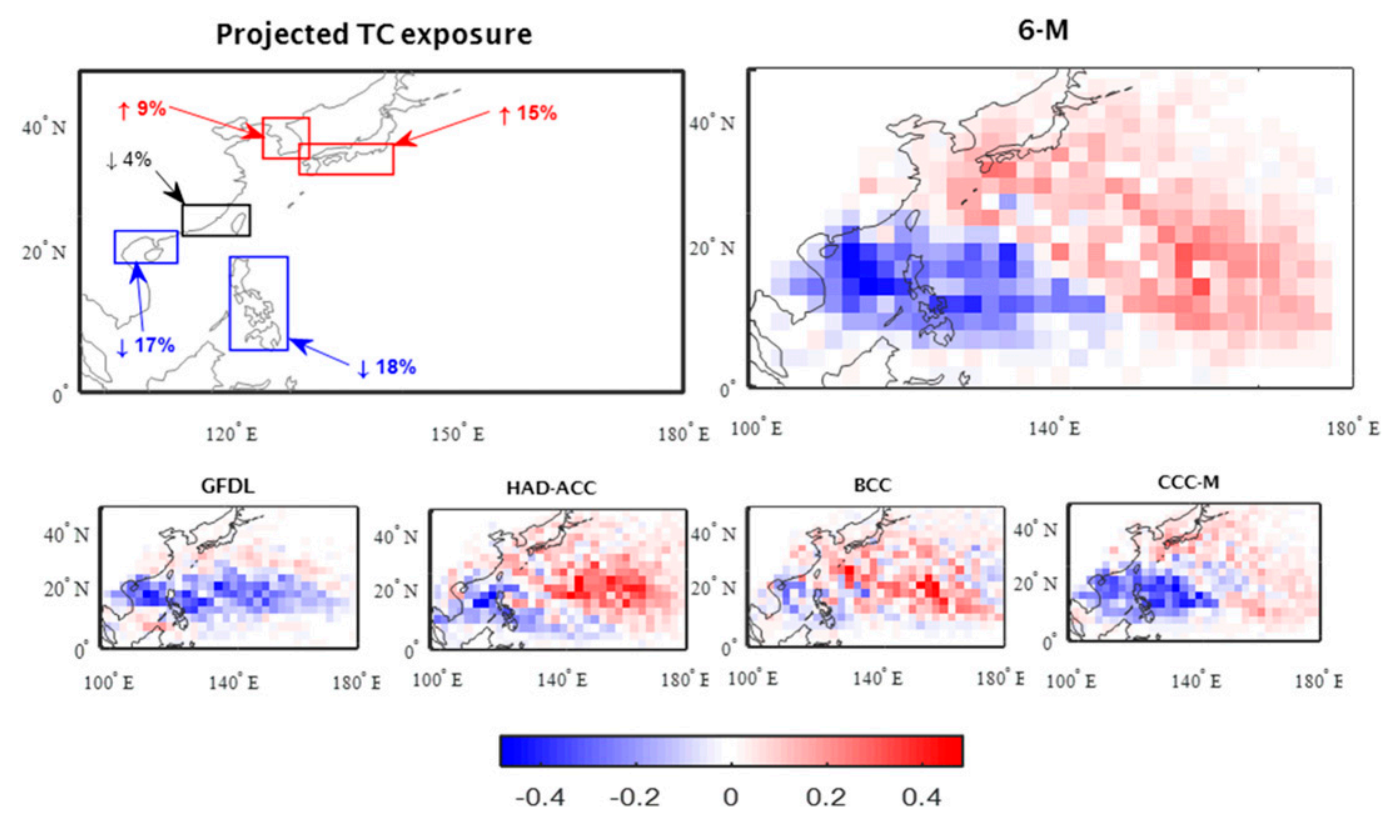

FIG. 5. The top left panel shows the defined regions of the Korean peninsula, Japan, eastern China, southern China, and the Philippines; arrows indicate the adjusted projected change of TC exposure between RCP8.5 and historical conditions. Projected changes significant at $95 \%$ are in red (increase) or blue (decrease). The remaining figures contain the projected change in annual TC activity $\left(2.5^{\circ}\right.$ grid) between RCP 8.5 and historical conditions, where red shading indicates a projected increase in activity.

Comparing projected TC frequencies (Table 4) between geographically close clusters with quite distinct trajectories [B (straight-westward) and A (recurvingnorthwestward), and D (straight-westward) and C (recurving-northwestward)] signals an increase in the number of TCs taking a northwestward track (i.e., belonging to clusters $\mathrm{A}$ and $\mathrm{E}$ ) rather than a westward track (i.e., belonging to clusters $\mathrm{B}$ and $\mathrm{D}$ ) under the RCP8.5 scenario, consistent with the findings of earlier studies (e.g., Colbert et al. 2015; Wang and Wu 2015).

\section{e. Changes in landfall activity}

The consequence of TC cluster frequency changes discussed in the prior section (see also section $3 \mathrm{f}$ for changes in large-scale environmental parameters) on landfalling events (TC exposure) in different regions is analyzed here. The following regions are defined (Fig. 5): the Korean peninsula $\left(34^{\circ}-40^{\circ} \mathrm{N}, 124^{\circ}-130^{\circ} \mathrm{E}\right)$, Japan $\left(32^{\circ}-38^{\circ} \mathrm{N}, 130^{\circ}-142^{\circ} \mathrm{E}\right)$, southern China $\left(18^{\circ}-\right.$ $\left.23^{\circ} \mathrm{N}, 104^{\circ}-112^{\circ} \mathrm{E}\right)$, eastern China $\left(22^{\circ}-26^{\circ} \mathrm{N}, 113^{\circ}-\right.$ $\left.123^{\circ} \mathrm{E}\right)$, and the Philippines $\left(6^{\circ}-19^{\circ} \mathrm{N}, 120^{\circ}-126^{\circ} \mathrm{E}\right)$. We define "TC exposure" as the number of individual TCs that either enter or form within the bounds of a region.

Significant changes in TC exposure were found for four out of the five regions, with results for eastern China (E-China) somewhat varied between model subgroups (Table 5). For the two most equatorward regions, southern China (S-China) and the Philippines, 17\% and

TABLE 5. Projected change (both raw and adjusted, $P_{\text {raw }}$ and $P_{\text {adj }}$ ) in TC exposure for the 6-M and four subgroup multimodel means. Model subgroup projection arrows represent the overall direction of change; arrows in bold indicate that each individual model member agrees on the direction of change. Bolding in the 6-M column indicates both $95 \%$ significant agreement between models and a $95 \%$ confidence interval either side of zero.

\begin{tabular}{|c|c|c|c|c|c|c|}
\hline \multirow[b]{3}{*}{ Region } & \multicolumn{6}{|c|}{ Model means } \\
\hline & \multicolumn{2}{|c|}{$6-\mathrm{M}$} & \multirow[b]{2}{*}{ HAD-ACC } & \multirow[b]{2}{*}{ GFDL } & \multirow[b]{2}{*}{ BCC } & \multirow[b]{2}{*}{ CCC-M } \\
\hline & $P_{\text {adj }}$ & $P_{\text {raw }}$ & & & & \\
\hline Korean peninsula & $\uparrow 9 \%$ & $(\uparrow 54 \%)$ & $\uparrow$ & $\uparrow$ & $\uparrow$ & $\uparrow$ \\
\hline Japan & $\uparrow 15 \%$ & $(\uparrow 67 \%)$ & $\uparrow$ & $\uparrow$ & $\uparrow$ & $\uparrow$ \\
\hline E-China & $\downarrow 4 \%$ & $(\downarrow 8 \%)$ & $\downarrow$ & $\uparrow$ & $\downarrow$ & $\downarrow$ \\
\hline S-China & $\downarrow 17 \%$ & $(\downarrow 28 \%)$ & $\downarrow$ & $\downarrow$ & $\downarrow$ & $\downarrow$ \\
\hline Philippines & $\downarrow 18 \%$ & $(\downarrow 25 \%)$ & $\downarrow$ & $\downarrow$ & $\downarrow$ & $\downarrow$ \\
\hline
\end{tabular}


TABLE 6. The cluster-specific contributions of TC exposure to the regions of the Korean peninsula, Japan, and the Philippines during historical and RCP8.5 climate simulations, and the projected change in exposure $\left(P_{\text {Exposure }}\right)$. Where appropriate, results that contribute little to a region's exposure were omitted. Calculations were made using a mean of six models (6-M). Raw projected TC frequencies for each cluster $\left(P_{\text {Frequencies }}\right)$ are also displayed for comparison, with bolding representing at least $90 \%$ confidence in that change, extracted from Table 4. Clusters are listed in order from most to least populous.

\begin{tabular}{|c|c|c|c|c|c|c|c|c|c|c|}
\hline \multirow[b]{2}{*}{$\begin{array}{c}P_{\text {Frequency }} \\
(\%)\end{array}$} & \multirow[b]{2}{*}{ Cluster } & \multicolumn{3}{|c|}{ Korean peninsula } & \multicolumn{3}{|c|}{ Japan } & \multicolumn{3}{|c|}{ Philippines } \\
\hline & & $\begin{array}{c}\text { Historical } \\
\left(\mathrm{yr}^{-1}\right)\end{array}$ & $\begin{array}{c}\mathrm{RCP8} 8.5 \\
\left(\mathrm{yr}^{-1}\right)\end{array}$ & $\begin{array}{c}P_{\text {Exposure }} \\
(\%)\end{array}$ & $\begin{array}{c}\text { Historical } \\
\left(\mathrm{yr}^{-1}\right)\end{array}$ & $\begin{array}{c}\mathrm{RCP} 8.5 \\
\left(\mathrm{yr}^{-1}\right)\end{array}$ & $\begin{array}{c}P_{\text {Exposure }} \\
(\%)\end{array}$ & $\begin{array}{c}\text { Historical } \\
\left(\mathrm{yr}^{-1}\right)\end{array}$ & $\begin{array}{c}\mathrm{RCP8} 8.5 \\
\left(\mathrm{yr}^{-1}\right)\end{array}$ & $\begin{array}{c}P_{\text {Exposure }} \\
(\%)\end{array}$ \\
\hline-1 & A & 0.2 & 0.2 & +24 & 0.3 & 0.4 & +35 & 0.5 & 0.5 & -10 \\
\hline-2 & $\mathrm{C}$ & & 0.1 & +44 & 0.2 & 0.3 & +55 & 0.1 & 0.1 & -46 \\
\hline-29 & B & & & & & & & 0.9 & 0.6 & -30 \\
\hline+13 & $\mathrm{E}$ & & & & 0.1 & 0.2 & +52 & & & \\
\hline+25 & $\mathrm{~F}$ & 0.06 & 0.13 & +127 & 0.4 & 0.8 & +104 & & & \\
\hline-17 & $\mathrm{H}$ & & & & & & & 1.1 & 0.7 & -37 \\
\hline-27 & $\mathrm{D}$ & & & & & & & 1.8 & 1.3 & -24 \\
\hline+70 & $\mathrm{G}$ & & & & & & & & & \\
\hline-6 & I & & & & & & & 0.8 & 0.7 & -12 \\
\hline & Total & 0.3 & 0.4 & +54 & 1.0 & 1.6 & +67 & 5.2 & 3.9 & -25 \\
\hline
\end{tabular}

$18 \%$ reductions in TC exposure were found respectively. For the subtropical regions, the Korean peninsula and Japan, TC activity was projected to significantly increase by $9 \%$ and $15 \%$ respectively. We note the adjusted projections of TC exposure for Japan and the Korean peninsula (Table 5) were heavily adjusted down due to only a few model tracks reaching these regions in comparison to the observed climatology. This increases the uncertainty of this result. The overall pattern of projected TC activity given by the 6-M mean (Fig. 5) is generally supported by results from other model subgroups (also in Fig. 5), although we note the GFDL models appear to project decreased exposure in the far east of the basin.

The contribution of each cluster to changes in TC exposure for each region was also considered (Tables 6 and 7). We note that projection results that were adjusted based on observed TC frequencies can complicate interpretations when comparing the numbers of TCs in a particular cluster that enter one of our five defined regions. Hence, only raw values are used in the discussions below. All values referred to can be found in Tables 6 and 7.

For example, the Korean peninsula is modulated by TCs from clusters A and F. In particular, we see that even though the projected changes in the actual number of TCs forming in clusters $\mathrm{A}$ and $\mathrm{F}$ are $1 \%$ and $25 \%$, respectively, the projected change in the number of TCs reaching the Korean peninsula from these clusters are $27 \%$ and $50 \%$, respectively (Table 6). Similarly, increasing TC exposure over southern Japan in the projected climate is found to be primarily from clusters A $(+35 \%), \mathrm{F}(+104 \%)$, and $\mathrm{E}(+52 \%)$, noting that the TC frequency in cluster $\mathrm{E}$ was projected to increase by just $13 \%$. These results indicate that more TCs are likely to track farther poleward in the projected warming climate as opposed to the historical climate. Further analysis isolating tracks in cluster $\mathrm{E}$ (not shown) indicated that TCs belonging to this cluster were more likely to follow a curving path into Japan in the projected

TABLE 7. As in Table 6, but for the eastern and southern China regions.

\begin{tabular}{|c|c|c|c|c|c|c|c|}
\hline \multirow[b]{2}{*}{$P_{\text {Frequency }}(\%)$} & \multirow[b]{2}{*}{ Cluster } & \multicolumn{3}{|c|}{ Eastern China } & \multicolumn{3}{|c|}{ Southern China } \\
\hline & & Historical $\left(\mathrm{yr}^{-1}\right)$ & $\mathrm{RCP} 8.5\left(\mathrm{yr}^{-1}\right)$ & $P_{\text {Exposure }}(\%)$ & Historical $\left(\mathrm{yr}^{-1}\right)$ & $\mathrm{RCP} 8.5\left(\mathrm{yr}^{-1}\right)$ & $P_{\text {Exposure }}(\%)$ \\
\hline-1 & A & 1.0 & 1.0 & +7 & 0.1 & 0.1 & \\
\hline-2 & $\mathrm{C}$ & 0.2 & 0.2 & -6 & & & \\
\hline-29 & B & 0.7 & 0.5 & -35 & 1.8 & 1.2 & -36 \\
\hline+13 & $\mathrm{E}$ & & & & & & \\
\hline+25 & $\mathrm{~F}$ & & & & & & \\
\hline-17 & $\mathrm{H}$ & & & & & & \\
\hline-27 & $\mathrm{D}$ & 0.3 & 0.3 & +8 & 0.3 & 0.3 & -2 \\
\hline+70 & $\mathrm{G}$ & & & & & & \\
\hline \multirow[t]{2}{*}{-6} & I & 0.1 & 0.1 & -9 & & & \\
\hline & Total & 2.3 & 2.1 & -8 & 2.3 & 1.7 & -28 \\
\hline
\end{tabular}


climate, rather than missing Japan to the south or east. Analysis of this finding is underway in a separate study but is beyond the scope of this paper. For the Philippines, we note that fewer straight moving TCs in the projected climate (i.e., clusters $\mathrm{B}$ and $\mathrm{D}$, and to some extent $\mathrm{H}$ ), compared to the historical climate, account for most of the reduced exposure $(-25 \%)$ to this region.

TCs impacting eastern China are strongly modulated by clusters A and B (Table 7). We note a slight increase $(+7 \%)$ in the number of TCs reaching eastern China from its dominant cluster (A) in the projected climate as opposed to the historical climate. In contrast, there is a substantial decrease of TC frequency in cluster B $(-29 \%)$ as well as a substantial decrease in the number of TCs eventually reaching eastern China from this cluster $(-35 \%)$. TCs reaching eastern China from cluster D are slightly increased $(+8 \%)$ compared to a reduction in this cluster's TC frequency $(-27 \%)$. Altogether these changes account for only a slight (insignificant) decrease in TC activity for the eastern China region (Table 5). Southern China is most strongly modulated by straight moving TCs in the South China Sea (cluster B). Fewer straight moving TCs (i.e., clusters B and D) under RCP8.5 substantially reduce TCs reaching southern China in the projected climate by $\sim 28 \%$.

\section{f. Role of large-scale conditions}

The relationship between TC genesis and certain largescale environmental parameters has been well documented since studies by Gray $(1968,1975)$. Here we analyze four large-scale fields, some of which are utilized by the OWZ TC detection scheme to identify TCs in model data, to better understand projected changes in TC genesis, and overall TC activity between the historical and projected climate simulations. Dynamical parameters evaluated were cyclonic relative vorticity at $850 \mathrm{hPa}$, environmental vertical wind shear between 850 and $200 \mathrm{hPa}$ and the vertical velocity $\omega$ at $500 \mathrm{hPa}$. We also examined the changes in midlevel relative humidity at $700 \mathrm{hPa}$. Values needed to compute these parameters (such as $u$ and $v$ components of winds at respective levels) were taken during the early to peak TC season in the WNP, (i.e., July-September). Environmental parameters were then composited over all seven models that form the 6-M, for the historical and RCP8.5 simulations, and their differences are displayed in Fig. 6. Regions where at least six out of the seven models agreed on the sign of change are marked with a crosshatch pattern.

In the South China Sea, we see significant increases in relative humidity but no discernible changes to vertical wind shear or omega. The differences in cyclonic vorticity ${ }^{3}$ (anticyclonic vorticity values were set to 0 before subtraction) between the projected and historical climates were consistent with decreased straight-moving TCs and more recurving TCs here, although only the former were found to be significant (Fig. 6a). Due to little indication of decreased favorability from other TC genesis parameters, it is likely that reductions in straight-moving TCs in the South China Sea are due to more TCs taking a northwestward track in the climate projection, as indicated by previous studies (Colbert et al. 2015; Wang and Wu 2015).

North of $20^{\circ} \mathrm{N}$, we see significant reductions in vertical wind shear, as well as increases in omega and relative humidity, supportive of enhanced TC genesis in cluster $\mathrm{F}$ and poleward track movement in clusters $\mathrm{F}, \mathrm{A}, \mathrm{E}$, and C. East of $165^{\circ} \mathrm{E}$ near the equator we see significant increases in relative humidity and ascending motion, consistent with increased TC frequency in cluster G.

\section{Discussion and summary}

Many studies in the past have looked at WNP TCs in the context of climate change using both fine-resolution model experiments as well as coarse-resolution models such as those from the CMIP experiments. However, most of these studies have utilized a model-dependent TC detection and tracking scheme proposed by Camargo and Zebiak (2002) or similar. While we note that no detector is perfect and that different detectors can produce different results when applied to the same model (Horn et al. 2014), use of a model- or resolution-dependent detection and tracking scheme can artificially conceal the true performance of a model by conflating model errors with detection errors (Tory et al. 2013a,b).

To facilitate thorough assessments of climate model performance over the WNP basin, and therefore enable more confidence in projection results, we utilized a model- and resolution-independent TC detection and tracking algorithm developed by Tory et al. (2013a), called Okubo-Weiss-Zeta (OWZ), that is fundamentally different in design from that applied in the prior studies. This scheme was applied to CMIP5 model simulations to determine projected changes in the WNP TCs between historical climate simulations (1970-2000) and projected climate simulations (2070-2100) under the RCP8.5 warming condition. Results were then compared

\footnotetext{
${ }^{3}$ It should also be noted that TCs themselves can be responsible for elevated levels of cyclonic vorticity, and to lesser extent ascending motion (i.e., more TCs occurring in a specific region may artificially inflate values over a 3-monthly mean like that seen in Fig. 6a). However, this would be unlikely to have a large impact on the results.
} 
(a) Cyclonic Vorticity (RCP8.5 - hist)

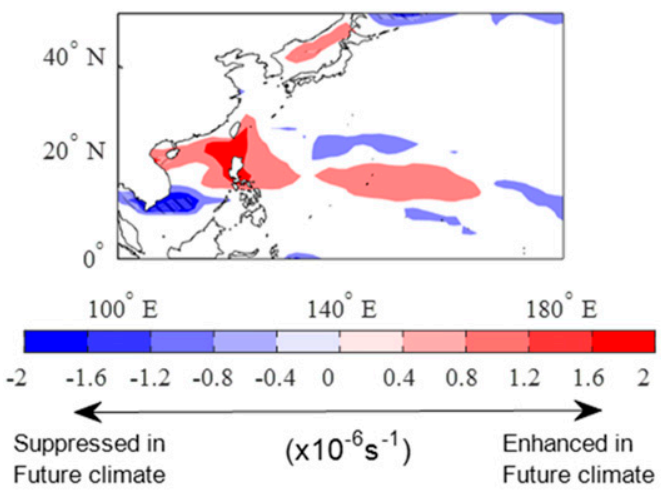

(c) Relative Humidity (RCP8.5 - hist)
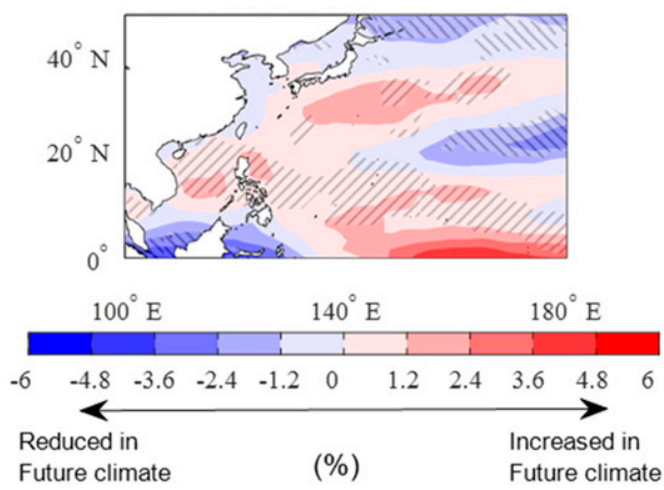

(b) Vertical Wind Shear (RCP8.5 - hist)

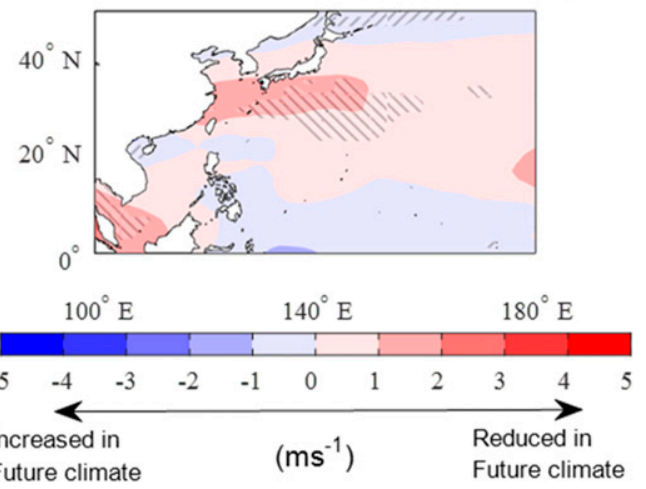

(d) Vertical $\omega$-velocity (RCP8.5 - hist)
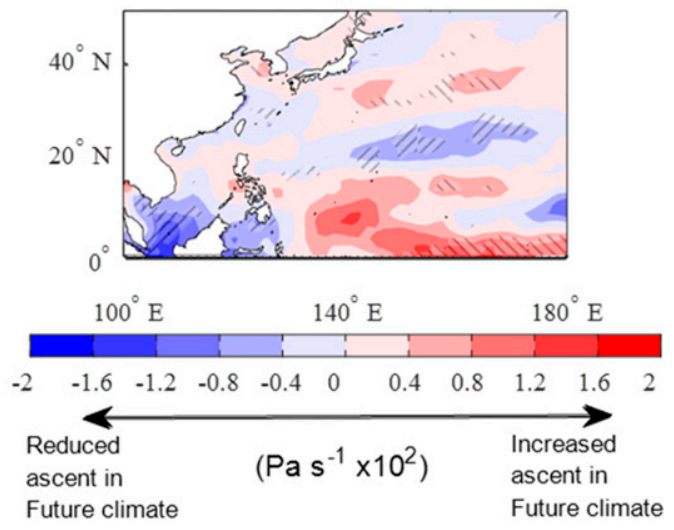

FIG. 6. Difference in the kernel densities of large-scale TC genesis parameters between RCP8.5 and historical conditions during the early-to-peak season months of July-September, averaged over each model used in the 6-M. Cross-hatching indicates at least $90 \%$ significance (agreement on sign between models). (a) Cyclonic relative vorticity at $850 \mathrm{hPa}$, (b) environmental vertical wind shear between 250 and $800 \mathrm{hPa}$, (c) relative humidity at $700 \mathrm{hPa}$, and (d) vertical omega velocity at $500 \mathrm{hPa}$. Red shading represents more favorable conditions for TC formation, noting (b) and (d) were multiplied by -1 .

with several similar studies in order to draw a consensus on WNP TC changes as a result of global warming. Despite often significant differences in the number of TCs detected between the Camargo and Zebiak (2002) scheme (the C-Z scheme) and OWZ detection scheme used in this study, the projection conclusions drawn are consistent with previous studies using the $\mathrm{C}-\mathrm{Z}$ scheme. This is a reassuring result that increases our confidence in the general results of this and previous papers.

TC tracks in the observed and model data were separated into nine clusters. While accounting for potential biases between historical and RCP8.5 climate simulations, projected changes in overall TC frequencies for each cluster were evaluated. Impacts of these clusterspecific changes on various subregions, relating to TC exposure in the WNP basin were also determined. The main results of this study are summarized as follows.
- In the future climate projection, TC frequencies of straight-moving TCs in the South China Sea (clusters B and D) were found to significantly decrease. There was no evidence of reductions, significant or otherwise, in the favorability of the large-scale TC genesis parameters analyzed except for a decrease in cyclonic vorticity close to the coastline. Therefore, these decreases are likely due to more TCs taking a northwestward track in the climate projection, as found by several other studies (e.g., Colbert et al. 2015; Wang and Wu 2015).

- TC frequencies in the eastern and upper segments of the basin, particularly those associated with clusters $\mathrm{F}$ and $G$, were found to significantly increase. These increases were consistent with increased favorability of the large-scale TC genesis parameters of vertical wind shear, relative humidity, and omega. These results are in line with other previous studies (e.g., Murakami et al. 2011; Kossin et al. 2016; Nakamura et al. 2017). 
TABLE A1. Parameter threshold values for the two sets of the OWZ-Detector's detection criteria; subscripts refer to the pressure level $(\mathrm{hPa})$.

\begin{tabular}{lccccc}
\hline \hline & \multicolumn{4}{c}{ Parameter thresholds } \\
\cline { 2 - 6 } Criterion & $\mathrm{OWZ}_{850}$ & $\mathrm{OWZ}_{500}$ & $\mathrm{RH}_{950}$ & $\mathrm{RH}_{700}$ & $\mathrm{VWS}_{850-200}$ \\
\hline Initial & $50 \times 10^{-6} \mathrm{~s}^{-1}$ & $40 \times 10^{-6} \mathrm{~s}^{-1}$ & $70 \%$ & $50 \%$ & $25 \mathrm{~m} \mathrm{~s}^{-1}$ \\
Core & $60 \times 10^{-6} \mathrm{~s}^{-1}$ & $50 \times 10^{-6} \mathrm{~s}^{-1}$ & $85 \%$ & $70 \%$ & $10 \mathrm{~g} \mathrm{~kg}^{-1}$ \\
\hline
\end{tabular}

- Significant changes in TC exposure were found in four subregions. For the two most equatorward regions, southern China and the Philippines, bias-corrected reductions in TC activity of $17 \%$ and $18 \%$ were found respectively. For the subtropical regions of the Korean peninsula and Japan, TC activity was projected to significantly increase by $9 \%$ and $15 \%$, respectively. These results are again consistent with earlier studies (e.g., Wang et al. 2011; Kossin et al. 2016; Park et al. 2017).

In closing, we do note that significant discrepancies between the low-resolution models used in this study embed a degree of uncertainty in the projection results, although these limitations were minimized by the methods used and confining the analysis to only appropriate TC characteristics. Furthermore, although findings in this study were supportive of many results found in prior papers, there were of course some disagreements among those existing studies [e.g., Colbert et al. (2015) found increases to the Korean peninsula and Japan to not be remarkable, in contrast to Kossin et al. (2016)], and therefore projection results to some extent remain uncertain. However, this study has potentially removed some of that uncertainty by supporting specific results without the caveats of the detector/tracker bias and model autocorrelation.

Acknowledgments. This work is supported through funding from the Earth Systems and Climate Change Hub of the Australian Government's National Environmental Science Programme (NESP). Samuel Bell is supported by an Australian Government Research Training Program (RTP) Stipend and RTP FeeOffset Scholarship through Federation University Australia. Suzana Camargo has partial support from the following NOAA grants: NA15OAR43100095, NA16OAR4310079, NA18OAR4310277.

\section{APPENDIX A}

\section{OWZ Detection and Tracking}

The OWZ detection system consists of six parameters (Table A1): minimum thresholds of OWZ at the 850- and 500-hPa levels, relative humidity (RH) at the 950- and 700$\mathrm{hPa}$ levels, specific humidity $(\mathrm{SpH})$ at the $950-\mathrm{hPa}$ level, and a maximum threshold of vertical wind shear (VWS) between 850 and $200 \mathrm{hPa}$. The OWZ variable is a low deformation vorticity parameter used to identify regions favorable for TC formation at the center of a semiclosed circulation (i.e., a "marsupial pouch"; Dunkerton et al. 2009), within the lower to middle troposphere. More precisely, it is the product of absolute vorticity and the Okubo-Weiss parameter (Okubo 1970; Weiss 1991) normalized by the vertical components of relative vorticity squared such that

$$
\mathrm{OWZ}=\operatorname{sgn}(f) \times(\zeta+f) \times \max \left[\frac{\zeta^{2}-\left(E^{2}+F^{2}\right)}{\zeta^{2}}, 0\right],
$$

where $f$ is the Coriolis parameter, $\zeta=(\partial v / \partial x)-(\partial u / \partial y)$ is the vertical component of relative vorticity, $E=$ $(\partial u / \partial x)-(\partial v / \partial y)$ is the stretching deformation, and $F=$ $(\partial v / \partial x)+(\partial u / \partial y)$ is the shearing deformation.

The OWZ detection and tracking scheme is concisely summarized in five points below, with further details accessible in other studies (Tory et al. 2013a; Bell et al. 2018).

1) Each $1^{\circ} \times 1^{\circ}$ grid point is assessed based on the initial threshold values of each OWZ-Detector parameter every $12 \mathrm{~h}$.

2) When at least two neighboring grid points satisfy the initial thresholds of each OWZ-Detector parameter, these points are considered to represent a single circulation at that point in time.

3) The circulations from item 2 are linked through time by estimating their position in relation to the circulation's expected position based on an averaged $4^{\circ} \times$ $4^{\circ}$ steering wind at $700 \mathrm{hPa}$.

4) Tracks are terminated when no circulation match is found in the next two time steps within a generous $(\sim 350 \mathrm{~km})$ latitude-dependent radius.

5) The core thresholds are then applied to each storm track, and if they are satisfied for $48 \mathrm{~h}$, a TC is declared.

\section{APPENDIX B}

\section{C-Z Track Alignment}

To properly align the tracks for comparison in Table 2, a similar track position as the TC declaration position (i.e., 

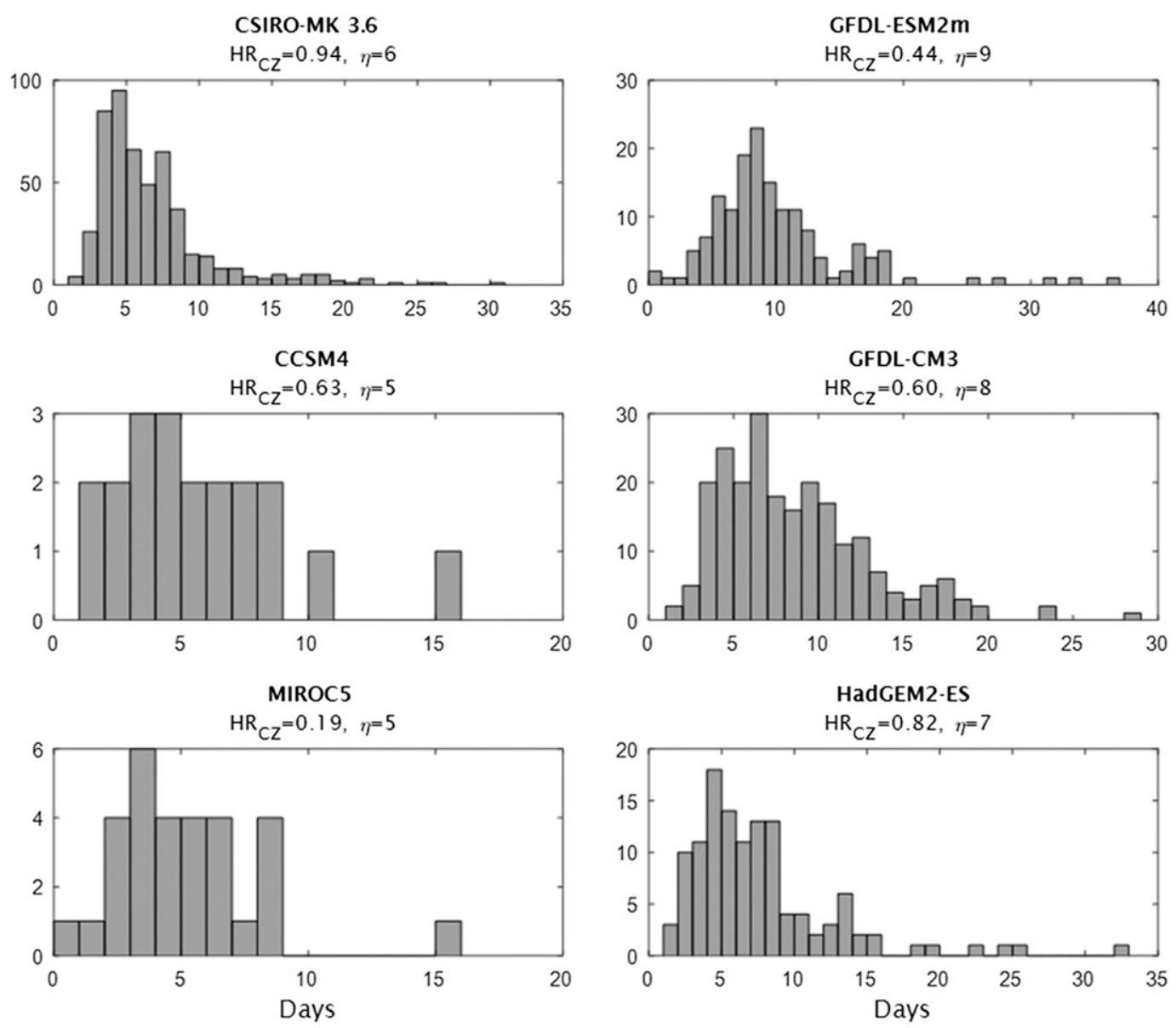

FIG. B1. Distribution of the match between model tracks detected with the C-Z detector and the TC genesis position of model tracks detected with the OWZ detector. $\mathrm{HR}_{\mathrm{CZ}}$ indicates the proportion of $\mathrm{C}-\mathrm{Z}$ detected tracks successfully matched to OWZ detected tracks for each model; $\eta$ indicates the median number of days a $\mathrm{C}-\mathrm{Z}$ track took to reach the OWZ genesis position.

genesis position for OWZ tracks) must be found for the $\mathrm{C}-\mathrm{Z}$ tracks. The genesis position of OWZ detected tracks were compared with matching $\mathrm{C}-\mathrm{Z}$ detected tracks in each model [the criteria for a track match or "hit" are the same as used in Bell et al. (2018)]. Results (Fig. B1) show that for the $\mathrm{C}-\mathrm{Z}$ tracks, a median of around 7 days after initial detection is the closest match to the TC genesis (or first) position of the OWZ tracks. Further analysis (not shown) found a positive relationship $(r=0.4)$ between the lifetime of a C-Z TC and the time it takes to reach the OWZ genesis position.

Therefore, it was decided to remove the median number of days (7) identified by Fig. B1 for TCs with lifetimes greater than 18 days. TCs with lifetimes of 18 days or less were trimmed according to a simple linear regression equation:

$$
\text { Track removed }=(0.32 \times \text { lifetime })+5.1
$$

where "Track removed" and "lifetime" are in the units of number of six-hourly time steps. For example, a TC with a lifetime of 18 days has 72 six-hourly time steps, and thus its "Track removed" would be 28 six-hourly time steps (7 days).

\section{REFERENCES}

Bell, S. S., S. S. Chand, K. J. Tory, and C. Turville, 2018: Statistical assessment of the OWZ tropical cyclone tracking scheme in ERA-Interim. J. Climate, 31, 2217-2232, https://doi.org/ 10.1175/JCLI-D-17-0548.1.

,,-- A. J. Dowdy, C. Turville, and H. Ye, 2019a: Projections of Southern Hemisphere tropical cyclone track density using CMIP5 models. Climate Dyn., 52, 6065-6079, https://doi.org/10.1007/s00382-018-4497-4.

, C. Turville, and H. Ye, 2019b: Eastern North Pacific tropical cyclone activity in historical and future CMIP5 experiments: Assessment with a model-independent tracking scheme. Climate Dyn., https://doi.org/10.1007/S00382-019-04830-0. 
Bengtsson, L., K. I. Hodges, M. Esch, N. Keenlyside, L. Kornblueh, J.-J. Luo, and T. Yamagata, 2007: How may tropical cyclones change in a warmer climate? Tellus, 59A, 539-561, https:// doi.org/10.1111/j.1600-0870.2007.00251.x.

Bi, D., and Coauthors, 2012: The ACCESS coupled model: Description, control climate and evaluation. Aust. Meteor. Oceanogr. J., 63, 41-64, https://doi.org/10.22499/2.6301.004.

Camargo, S. J., 2013: Global and regional aspects of tropical cyclone activity in the CMIP5 models. J. Climate, 26, 9880-9902, https://doi.org/10.1175/JCLI-D-12-00549.1.

, and S. E. Zebiak, 2002: Improving the detection and tracking of tropical cyclones in atmospheric general circulation models. Wea. Forecasting, 17, 1152-1162, https://doi.org/10.1175/15200434(2002)017<1152:ITDATO>2.0.CO;2.

, A. W. Robertson, S. J. Gaffney, P. Smyth, and M. Ghil, 2007a: Cluster analysis of typhoon tracks. Part I: General properties. J. Climate, 20, 3635-3653, https://doi.org/ 10.1175/JCLI4188.1.

,,,---- , and $-2007 \mathrm{~b}$ : Cluster analysis of typhoon tracks: Part II: Large-scale circulation and ENSO. J. Climate, 20, 3654-3676, https://doi.org/10.1175/JCLI4203.1.

— A. H. Sobel, A. D. Delgenio, J. A. Jonas, M. Kelley, Y. Lu, D. A. Shaevitz, and N. Henderson, 2016: Tropical cyclones in the GISS ModelE2. Tellus, 68A, 31494, https://doi.org/ 10.3402/tellusa.v68.31494.

Chand, S. S., K. J. Tory, H. Ye, and K. J. E. Walsh, 2017: Projected increase in El Niño-driven tropical cyclone frequency in the Pacific. Nat. Climate Change, 7, 123-127, https://doi.org/ 10.1038/nclimate3181.

Colbert, A. J., B. J. Soden, and B. P. Kirtman, 2015: The impact of natural and anthropogenic climate change on western North Pacific tropical cyclone tracks. J. Climate, 28, 1806-1823, https://doi.org/10.1175/JCLI-D-14-00100.1.

Collier, M. A., and Coauthors, 2011: The CSIRO-Mk3.6.0 atmosphere-ocean GCM: Participation in CMIP5 and data publication. Proc. 19th Int. Congress on Modelling and Simulation, Perth, Australia, 2691-2697, http://mssanz.org.au/ modsim2011.

Davis, C. A., 2018: Resolving tropical cyclone intensity in models. Geophys. Res. Lett., 45, 2082-2087, https://doi.org/10.1002/ 2017GL076966.

Donner, L. J., and Coauthors, 2011: The dynamical core, physical parameterizations, and basic simulation characteristics of the atmospheric component AM3 of the GFDL global coupled model CM3. J. Climate, 24, 3484-3519, https://doi.org/10.1175/ 2011JCLI3955.1.

Dunkerton, T. J., M. T. Montgomery, and Z. Wang, 2009: Tropical cyclogenesis in a tropical wave critical layer: Easterly waves. Atmos. Chem. Phys., 9, 5587-5646, https://doi.org/10.5194/ acp-9-5587-2009.

Emanuel, K. A., 2013: Downscaling CMIP5 climate models shows increased tropical cyclone activity over the 21st century. Proc. Natl. Acad. Sci. USA, 110, 12219-12224, https://doi.org/ 10.1073/pnas.1301293110.

Gaffney, S. J., 2004: Probabilistic curve-aligned clustering and prediction with regression mixture models. Ph.D. thesis, University of California, Irvine, CA, 281 pp., http://www.ics.uci. edu/pub/sgaffney/outgoing/sgaffney_thesis.pdf.

, A. W. Robertson, P. Smyth, S. J. Camargo, and M. Ghil, 2007: Probabilistic clustering of extratropical cyclones using regression mixture models. Climate Dyn., 29, 423-440, https:// doi.org/10.1007/s00382-007-0235-z.
Gao, S., Z. Chen, and W. Zhang, 2018: Impacts of tropical North Atlantic SST on western North Pacific landfalling tropical cyclones. J. Climate, 31, 853-862, https://doi.org/10.1175/JCLID-17-0325.1.

Gent, P. R., and Coauthors, 2011: The Community Climate System Model version 4. J. Climate, 24, 4973-4991, https://doi.org/ 10.1175/2011JCLI4083.1.

Gray, W. M., 1968: Global view of the origin of tropical disturbances and storms. Mon. Wea. Rev., 96, 669-700, https://doi.org/10.1175/ 1520-0493(1968)096<0669:GVOTOO>2.0.CO;2.

_ 1975: Tropical cyclone genesis. Dept. of Atmospheric Science Paper 234, Colorado State University, 121 pp.

Harr, P. A., and R. L. Elsberry, 1995: Large-scale circulation variability over the tropical western North Pacific. Part I: Spatial patterns and tropical cyclone characteristics. Mon. Wea. Rev., 123, 1225-1246, https://doi.org/10.1175/1520-0493(1995) $123<1225:$ LSCVOT $>2.0 . \mathrm{CO} ; 2$.

Hawkins, E., T. M. Osbourne, C. K. Ho, and A. J. Challinor, 2013: Calibration and bias correction of climate projections for crop modelling: An idealised case study over Europe. Agric. For. Meteor., 170, 19-31, https://doi.org/10.1016/ j.agrformet.2012.04.007.

Held, I. M., and M. Zhao, 2011: The response of tropical cyclone statistics to an increase in $\mathrm{CO}_{2}$ with fixed sea surface temperatures. J. Climate, 24, 5353-5364, https://doi.org/10.1175/ JCLI-D-11-00050.1.

Ho, C. K., D. B. Stephenson, M. Collins, C. A. T. Ferro, and S. J. Brown, 2012: A source of additional uncertainty in climate change projections. Bull. Amer. Meteor. Soc., 93, 21-26, https://doi.org/10.1175/2011BAMS3110.1.

Horn, M., and Coauthors, 2014: Tracking scheme dependence of simulated tropical cyclone response to idealized climate simulations. J. Climate, 27, 9197-9213, https://doi.org/10.1175/ JCLI-D-14-00200.1.

Jin, C.-S., D.-H. Cha, M.-S. Suh, S.-Y. Hong, H.-S. Kang, and C.-H. Ho, 2016: Evaluation of climatological tropical cyclone activity over the western North Pacific in the CORDEX-East Asia multi-RCM simulations. Climate Dyn., 47, 765-778, https://doi.org/10.1007/s00382-015-2869-6.

Jones, C. D., and Coauthors, 2011: The HadGEM2-ES implementation of CMIP5 centennial simulations. Geosci. Model Dev., 4, 543-570, https://doi.org/10.5194/gmd-4-5432011.

JTWC, 2017: JTWC best track dataset. Subset used: January 1979_ December 2013, accessed 7 September 2017, Joint Typhoon Warning Center, https://www.usno.navy.mil/NOOC/nmfc-ph/ RSS/jtwc/best_tracks/.

Knutson, T. R., and Coauthors, 2015: Global projections of intense tropical cyclone activity for the late twenty-first century from dynamical downscaling of CMIP5/RCP4.5 scenarios. J. Climate, 28, 7203-7224, https://doi.org/10.1175/JCLI-D-150129.1.

Knutti, R., D. Masson, and A. Gettelman, 2013: Climate model genealogy: Generation CMIP5 and how we got there. Geophys. Res. Lett., 40, 1194-1199, https://doi.org/10.1002/ grl.50256.

Kossin, J. P., K. A. Emanuel, and S. J. Camargo, 2016: Past and projected changes in western North Pacific tropical cyclone exposure. J. Climate, 29, 5725-5739, https://doi.org/10.1175/ JCLI-D-16-0076.1.

Meehl, G. A., C. Covey, T. Delworth, M. Latif, B. McAvaney, J. F. B. Mitchell, R. J. Stouffer, and K. R. Taylor, 2007: THE WCRP CMIP3 multimodel dataset: A new era in climate 
change research. Bull. Amer. Meteor. Soc., 88, 1383-1394, https://doi.org/10.1175/BAMS-88-9-1383.

Moise, A., and Coauthors, 2015: Evaluation of CMIP3 and CMIP5 models over the Australian region to inform confidence in projections. Aust. Meteor. Oceanogr. J., 65, 19-53, https:// doi.org/10.22499/2.6501.004.

Mori, M., and Coauthors, 2013: Hindcast prediction and nearfuture projection of tropical cyclone activity over the western North Pacific using CMIP5 near-term experiments with MIROC. J. Meteor. Soc. Japan, 91, 431-452, https://doi.org/ 10.2151/jmsj.2013-402.

Murakami, H., B. Wang, and A. Kitoh, 2011: Future change of western North Pacific typhoons: Projections by a 20-km-mesh global atmospheric model. J. Climate, 24, 1154-1169, https:// doi.org/10.1175/2010JCLI3723.1.

_- R. Mizuta, and E. Shindo, 2012a: Future changes in tropical cyclone activity projected by multi-physics and multi-SST ensemble experiments using the 60-km-mesh MRI-AGCM Climate Dyn., 39, 2569-2584, https://doi.org/10.1007/s00382011-1223-x.

— , and Coauthors, 2012b: Future changes in tropical cyclone activity projected by the new high-resolution MRI-AGCM. J. Climate, 25, 3237-3260, https://doi.org/10.1175/JCLI-D-1100415.1

_ , and Coauthors, 2015: Simulation and prediction of category 4 and 5 hurricanes in the high-resolution GFDL HiFLOR coupled climate model. J. Climate, 28, 9058-9079, https://doi.org/ 10.1175/JCLI-D-15-0216.1.

Nakamura, J., and Coauthors, 2017: Western North Pacific tropical cyclone model tracks in present and future climates. J. Geophys. Res. Atmos., 122, 9721-9744, https://doi.org/ 10.1002/2017JD02700.

Okubo, A., 1970: Horizontal dispersion of floatable particles in the vicinity of velocity singularities such as convergences. DeepSea Res., 17, 445-454, https://doi.org/10.1016/0011-7471(70) 90059-8.

Park, D.-S. R., C.-H. Ho, J. C. L. Chan, K.-J. Ha, H.-S. Kim, J. Kim, and J.-H. Kim, 2017: Asymmetric response of tropical cyclone activity to global warming over the North Atlantic and western North Pacific from CMIP5 model projections. Sci. Rep., 7, 41354, https://doi.org/10.1038/ srep41354.

Patricola, C. M., S. J. Camargo, P. J. Klotzbach, R. Saravanan, and P. Chang, 2018: The influence of ENSO flavors on western North Pacific tropical cyclone activity. J. Climate, 31, 53955416, https://doi.org/10.1175/JCLI-D-17-0678.1.

Riahi, K., and Coauthors, 2011: RCP 8.5-A scenario of comparatively high greenhouse gas emissions. Climatic Change, $\mathbf{1 0 9}$ 33-57, https://doi.org/10.1007/s10584-011-0149-y.

Sanderson, B., R. Knutti, and P. Caldwell, 2015: A representative democracy to reduce interdependency in a multimodel ensemble. J. Climate, 28, 5171-5194, https://doi.org/10.1175/ JCLI-D-14-00362.1.

Scoccimarro, E., and Coauthors, 2011: Effects of tropical cyclones on ocean heat transport in a high-resolution coupled general circulation model. J. Climate, 24, 4368-4384, https://doi.org/ 10.1175/2011JCLI4104.1.

Shaevitz, D. A., and Coauthors, 2014: Characteristics of tropical cyclones in high-resolution models of the present climate. J. Adv. Model. Earth Syst., 6, 1154-1172, https://doi.org/ 10.1002/2014MS000372.

Stowasser, M., Y. Wang, and K. Hamilton, 2007: Tropical cyclone changes in the western North Pacific in a global warming scenario. J. Climate, 20, 2378-2396, https://doi.org/10.1175/ JCLI4126.1.

Strachan, J., P. L. Vidale, K. Hodges, M. Roberts, and M.-E. Demory, 2013: Investigating global tropical cyclone activity with a hierarchy of AGCMs: The role of model resolution. J. Climate, 26, 133-152, https://doi.org/10.1175/JCLI-D-1200012.1.

Sugi, M., H. Murakami, and J. Yoshimura, 2009: A reduction in global tropical cyclone frequency due to global warming. SOLA, 5, 164-167, https://doi.org/10.2151/SOLA.2009-042.

Taylor, K. E., R. J. Stouffer, and G. A. Meehl, 2012: An overview of CMIP5 and the experiment design. Bull. Amer. Meteor. Soc., 93, 485-498, https://doi.org/10.1175/BAMS-D-11-00094.1.

Tory, K. J., and R. A. Dare, 2015: Sea surface temperature thresholds for tropical cyclone formation. J. Climate, 28, 81718183, https://doi.org/10.1175/JCLI-D-14-00637.1.

,,-- N. E. Davidson, J. L. McBride, and S. S. Chand, 2013a: The importance of low-deformation vorticity in tropical cyclone formation. Atmos. Chem. Phys., 13, 2115-2132, https:// doi.org/10.5194/acp-13-2115-2013.

, S. S. Chand, R. A. Dare, and J. L. McBride, 2013b: The development and assessment of a model-, grid-, and basin independent tropical cyclone detection scheme. J. Climate, 26, 5493-5507, https://doi.org/10.1175/JCLI-D-12-00510.1.

,,,- J. L. McBride, H. Ye, and R. A. Dare, 2013c: Projected changes in late-twenty-first-century tropical cyclone frequency in 13 coupled climate models from phase 5 of the Coupled Model Intercomparison Project. J. Climate, 26, 9946 9959, https://doi.org/10.1175/JCLI-D-13-00010.1.

,,,--- and,- 2014 : Projected changes in late 21st century tropical cyclone frequency in CMIP5 models. Proc. 31st Conf. on Hurricanes and Tropical Meteorology, San Diego, CA, Amer. Meteor. Soc., 7C.4, https://ams.confex.com/ ams/31Hurr/webprogram/Paper245100.html.

-, H. Ye, and R. A. Dare, 2018: Understanding the geographic distribution of tropical cyclone formation for applications in climate models. Climate Dyn., 50, 2489-2512, https://doi.org/ 10.1007/s00382-017-3752-4.

Tsou, C.-H., P.-Y. Huang, C.-Y. Tu, C.-T. Chen, T.-P. Tzeng, and C. T. Cheng, 2016: Present simulation and future typhoon activity projection over western North Pacific and Taiwan/east coast of China in 20-km HiRAM climate model. Terr. Atmos. Oceanic Sci., 27, 687-703, https://doi.org/10.3319/TAO.2016. 06.13.04.

van Vuuren, D. P., and Coauthors, 2011: The representative concentration pathways: An overview. Climatic Change, 109, 531, https://doi.org/10.1007/s10584-011-0148-z.

Vecchi, G. A., S. Fueglistaler, I. M. Held, T. R. Knutson, and M. Zhao, 2013: Impacts of atmospheric temperature trends on tropical cyclone activity. J. Climate, 26, 3877-3891, https:// doi.org/10.1175/JCLI-D-12-00503.1.

_ , and Coauthors, 2014: On the seasonal forecasting of regional tropical cyclone activity. J. Climate, 27, 7994-8016, https:// doi.org/10.1175/JCLI-D-14-00158.1.

Voldoire, A., and Coauthors, 2013: The CNRM-CM5.1 global climate model: Description and basic evaluation. Climate Dyn., 40, 2091-2121, https://doi.org/10.1007/s00382-0111259-y.

Walsh, K. J. E., M. Fiorino, C. W. Landsea, and K. L. McInnes, 2007: Objectively determined resolution-dependent threshold criteria for the detection of tropical cyclones in climate models and reanalyses. J. Climate, 20, 2307-2314, https://doi.org/ 10.1175/JCLI4074.1. 
_ S. Lavender, E. Scoccimarro, and H. Murakami, 2013: Resolution dependence of tropical cyclone formation in CMIP3 and finer resolution models. Climate Dyn., 40, 585-599, https:// doi.org/10.1007/s00382-012-1298-z.

Wang, C., and L. Wu, 2015: Influence of future tropical cyclone track changes on their basin-wide intensity over the western North Pacific: Downscaled CMIP5 projections. Adv. Atmos. Sci., 32, 613-623, https://doi.org/10.1007/s00376-014-4105-4.

Wang, R., L. Wu, and C. Wang, 2011: Typhoon track changes associated with global warming. J. Climate, 24, 3748-3752, https://doi.org/10.1175/JCLI-D-11-00074.1.

Watanabe, M., and Coauthors, 2010: Improved climate simulation by MIROC5: Mean states, variability, and climate sensitivity. J. Climate, 23, 6312-6335, https://doi.org/10.1175/2010JCLI3679.1.

Wehner, M., Prabhat, K. A. Reed, D. Stone, W. D. Collins, and J. Bacmeister, 2015: Resolution dependence of future tropical cyclone projections of CAM5.1 in the U.S. CLIVAR Hurricane Working Group idealized configurations. J. Climate, 28, 3905-3925, https://doi.org/10.1175/JCLI-D-14-00311.1.

Weiss, J., 1991: The dynamics of enstrophy transfer in twodimensional hydrodynamics. Physica D, 48, 273-294, https:// doi.org/10.1016/0167-2789(91)90088-Q.

Wu, M. C., W. L. Chang, and W. M. Leung, 2004: Impacts of El Niño-Southern Oscillation events on tropical cyclone landfalling activity in the western North Pacific. J. Climate, 17, 1419-1428, https://doi.org/10.1175/1520-0442(2004)017<1419: IOENOE $>2.0 . C O ; 2$.
Wu, T., and Coauthors, 2014: An overview of BCC climate system model development and application for climate change studies. J. Meteor. Res., 28, 34-56, http://dx.doi.org/10.1007/ S13351-014-3041-7.

Yokoi, S., Y. N. Takayabu, and H. Murakami, 2013: Attribution of projected future changes in tropical cyclone passage frequency over the western North Pacific. J. Climate, 26, 4096-4111, https://doi.org/10.1175/JCLI-D-12-00218.1.

Zarzycki, C. M., and P. A. Ullrich, 2017: Assessing sensitivities in algorithmic detection of tropical cyclones in climate data. Geophys. Res. Lett., 44, 1141-1149, https://doi.org/10.1002/ 2016 GL071606.

Zhang, W., G. A. Vecchi, G. Villarini, H. Murakami, R. Gudgel, and X. Yang, 2017: Statistical-dynamical seasonal forecast of western North Pacific and East Asia landfalling tropical cyclones using the GFDL FLOR coupled climate model. J. Climate, 30, 2209-2232, https://doi.org/10.1175/JCLI-D-160487.1.

Zhang, W.-Q., L.-G. Wu, and X.-K. Zou, 2018: Changes of tropical cyclone tracks in the western North Pacific over 1979-2016. Adv. Climate Change Res., 9, 170-176, https://doi.org/10.1016/ J.ACCRE.2018.06.002.

Zhao, M., I. M. Held, S.-J. Lin, and G. A. Vecchi, 2009: Simulations of global hurricane climatology, interannual variability, and response to global warming using a $50-\mathrm{km}$ resolution GCM. J. Climate, 22, 6653-6678, https://doi.org/10.1175/ 2009JCLI3049.1. 